\title{
El cuidado infantil: Respuestas a las necesidades de madres que trabajan y sus hijos
}

Caroline Arnold

Jorge Mejia

Aster Haregot

Ann Leonard

Cassie Landers

Follow this and additional works at: https://knowledgecommons.popcouncil.org/departments_sbsr-pgy

Part of the Family, Life Course, and Society Commons, Gender and Sexuality Commons, International Public Health Commons, Maternal and Child Health Commons, and the Work, Economy and Organizations Commons

How does access to this work benefit you? Let us know!

\section{Recommended Citation}

Arnold, Caroline, Jorge Mejia, Aster Haregot, Ann Leonard, and Cassie Landers. 1992. "El cuidado infantil: Respuestas a las necesidades de madres que trabajan y sus hijos," SEEDS no. 13. New York: Population Council. 


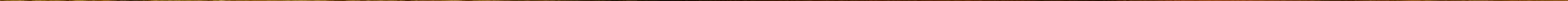


SEEDS es una serie de folletos creados para responder a las solicitudes recibidas de todos los sitios del mundo acerca de informatión sobre programas nuevos y prácticos desarrollados para y por mujeres de bajos ingresos. El objecto de estos folletos es, en consecuencia, distribuir información y estimular la creación de proyectos nuevos, basados en las experiencias positivas de aquellas mujeres que trabajan para ayudarse a si mismas y para ayudar a que otras mujeres eleven su nivel económico. Los programas que se describen en este y en otros números de SEEDS se han elegido porque les ofrecen a las mujeres la oportunidad de recibir ingresos en efectivo, de tomar decisiones y de ganar dinero; se basan en un criterio económico sensato y han solucionado con éxito los problemas que con frecuencia tienen que afrontar tales mujeres. Estos informes no pretenden dar reglas fijas, puesto que cada programa de desarrollo tendrá que enfrentar problemas un poco diferentes y contará con medios diferentes. El propósito ha sido más bien describir la historia de una idea y su implementación, en la esperanza de que las lecciones aprendidas puedan utilizarse en una gran variedad de situaciones. Se ha escrito sobre estos programas, además, para poner de presente a quienes están en posiciones directivas el hecho de que los programas para mujeres que son generadores de ingresos y están realizados por ellas, son factibles y representan un papel importante en los procesos del desarrollo.

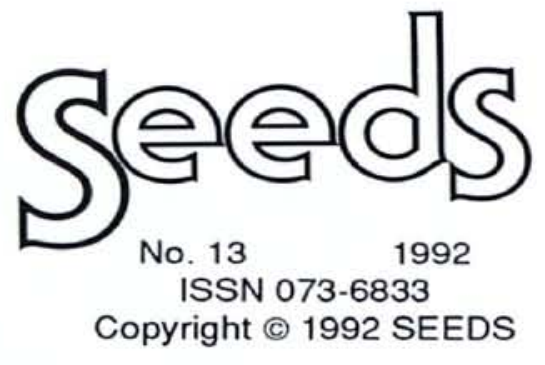

La edición No. 13 en inglés se publicó en 1991.
El apoyo administrativo y la dirección de los proyectos de SEEDS los provee The Population Council. La politica editorial le determina el SEEDS Steering Committee: Judith Bruce (The Population Council), Betsy Campbell (The Ford Foundation), Marty Chen (Harvard Institute for International Development), Margaret Clark (The Aspen Institute), Anne Kubisch (The Ford Foundation), Cecilia Lotse (UNICEF), Ann Leonard (The Population Council), Katharine McKee (Center for Community Self-Help), Anne Walker (International Women's Tribune Center), and Mildred Warner (Cornell University).

La traducción de esta edición de SEEDS al español fue subvencionada por la Fundación Rockefeller.

Las exposicioines y los puntos de vista expresados en esta publicación son total responsabilidad del autores y no de las organizaciones que proveen su apoyo a SEEDS. 


\title{
El Cuidado Infantil: Respuestas a las Necesidades de Madres que Trabajan y Sus Hijos
}

\author{
Ann Leonard y \\ Cassie Landers, editoras
}

\author{
Informes de \\ Caroline Arnold: Nepal \\ Jorge Mejía: Ecuador \\ Aster Haregot: Etiopía
}

\section{Introducción}

Durante la década de los ochenta se le prestó mucha atención a las iniciativas programáticas en los ámbitos de "mujer y desarrollo" y "desarrollo infantil". Pero generalmente cada uno de estos enfoques ha contado con sus propios promotores y practicantes, y con un programa particular para la acción. En pocos casos se ha reconocido que ambos enfoques se dirigen al mismo grupo de beneficiarias: las mujeres con hijos pequeños (infantes y preescolares). En la actualidad la mayoria de las mujeres del mundo en vias de desarrollo, asi como las de los paises desarrollados, deben trabajar fuera del hogar para asegurar la supervivencia y el bienestar de sus familias. Inevitablemente, todas estas mujeres se enfrentan con el angustioso dilema de determinar quién cuidará a sus hijos mientras ellas están trabajando. Y más allá de asegurar que alguien esté con ellos, las madres deben preocuparse por la calidad del cuidado que recibirán sus hijos, porque ésta afecta la salud, la capacidad de socialización y el desarrollo intelectual de los mismos.

En esta edición de SEEDS (desarrollada en cooperación con el Grupo Asesor sobre Cuidado y Desarrollo Infantil, y apoyada por UNICEF), hemos buscado reunir los elementos críticos del trabajo de la mujer y el cuidado infantil, estudiando el tema desde tres perspectivas: el cuidado infantil como servicio que permite que la mujer pueda trabajar, como fuente de empleo para la mujer, y como respuesta a los requerimientos del desarrollo infantil. Examinamos tres distintos tipos de cuidado infantil apoyados por UNICEF en tres continentes: Asia (Nepal), Africa (Etiopia) y América Latina (Ecuador). Los tres proyectos fueron desarrollados especificamente para madres que trabajan, y dos también son parte de programas que apoyan actividades económicas para la mujer.

Estos proyectos no sólo han servido como soluciones positivas para mujeres que trabajan, sino que han hecho posible que muchas de ellas reciban entrenamiento y desarrollen capacidades de administración y liderazgo, además de conseguir empleos como cuidadoras infantiles. 


\section{El trabajo de la mujer y el cuidado infantil}

"En el mundo en vias de desarrollo, son ellas las que se encargan de cultivar la mayoria de los alimentos, de llevar al mercado la gran parte de las cosechas, de buscar el agua, recolectar la leña, alimentar a los animales, y desyerbar los campos.

Y cuando terminan sus tareas fuera del hogar, son ellas las que se encargan de encender los fuegos, cocinar las comidas, limpiar la casa, lavar la ropa, comprar lo necesario y cuidar a los enfermos y los ancianos.

Y como si fuera poco, son ellas las que dan a luz y cuidan a los niños".'

La gran mayoria de las madres en el mundo de hoy trabajan para generar ingresos. Ya sea en sus propias viviendas, en campos y mercados locales, o en parques industriales y empresas urbanas, las mujeres de los países en vías de desarrollo, tanto como las del mundo desarrollado, generan ingresos para apoyarse a sí mismas, a sus hijos y a sus familias. En 1985, el indice oficial de participación femenina en el ámbito laboral mundial alcanzaba el 32\%. En la India, por ejemplo, las mujeres estaban contribuyendo el 36\% del producto doméstico total de la nación, sin contar su trabajo doméstico. De hecho, desde 1950 el ritmo de crecimiento de la participación de la mujer en la mano de obra ha sido dos veces mayor al de los varones. ${ }^{2}$

Aunque las mujeres del Tercer Mundo siempre han tenido que apoyar a sus familias a través del trabajo, los efectos de la industrialización, la urbanización, la migración y la severa recesión económica mundial de la década de los ochenta han obligado a que muchas más tengan que buscar empleos pagados. Generalmente, las mujeres mantienen estos empleos a la vez que continúan cumpliendo con sus indispensables responsabilidades de producción doméstica. Una proporción aún mayor de mujeres deben trabajar en el sector económico informal, donde los sueldos suelen ser bajos e inseguros. ${ }^{3}$ Estos factores, combinados con cambios en las normas sociales, han resultado además en un crecimiento del número de mujeres que representan la fuente principal de apoyo económico de sus familias. En Ghana se ha calculado que más del 29\% de los hogares están encabezados por mujeres, ${ }^{4}$ y en algunas sociedades esta proporción llega al 50\% del los hogares con niños. Marianne Schmink, en su estudio La mujer, la familia de bajos ingresos y los servicios urbanos en América Latina, señala que "muchas mujeres de familias de clase obrera representan la única o la principal fuente de ingresos", y que "para las madres, el acceso a algún tipo de cuidado infantil es probablemente el factor más importante en cuanto a la posibilidad de participar en actividades que generan ingresos". 5

\section{Las madres que trabajan}

No sólo está aumentando el número de madres que trabajan; también está creciendo la proporción de madres con niños pequeños que deben viajar cada vez más lejos del hogar para llegar al lugar de empleo, tanto en el sector tradicional como en el moderno. Aunque resulta difícil encontrar estadisticas específicas sobre el número de madres que trabajan en la mayoría del mundo, y especialmente en situaciones donde predominan empleos en el sector informal, se sabe que actualmente cerca del $57 \%$ de las mujeres estadounidenses con hijos menores de seis años tienen empleos, y que la cifra parece estar aumentando. ${ }^{6}$ El número de mujeres estadounidenses que volvieron al trabajo antes de cumplirse un año de haber dado a luz, por ejemplo, aumentó del 31\% en 1976 al 50,8\% en $1987 . ?$ Los resultados del Estudio de Alimentación Infantil en Bangkok, Tailandia, indicaron que alrededor de un tercio de las madres en la encuesta habian vuelto al trabajo durante el primer año de vida de la criatura: el 20\% a los dos meses del parto y el $31 \%$ antes de que el niño cumpliera un año. En Nairobi, Kenia, el 25\% de las madres habian vuelto al trabajo a los seis meses de haber dado a luz, y el 29\% habian vuelto cuando sus criaturas tenian entre nueve y diez meses de vida. ${ }^{8}$

Obviamente, todas estas madres también deben conseguir que alguien cuide a sus hijos mientras están en el trabajo, ya que en todas partes del mundo la provisión de una solución adecuada al dilema del cuidado infantil sigue siendo la responsabilidad de la mujer. "La paternidad tiene un efecto directo sobre la disponibilidad de tiempo para la mujer, mientras que casi no afecta el horario del varón," observan Dwyer y Bruce. ${ }^{9}$ La búsqueda de un equilibro entre la necesidad de trabajar y de garantizar la seguridad y el bienestar de sus hijos resulta cada vez más angustiosa para la mujer de hoy. La ansiedad que ésto provoca sólo se puede aliviar con el acceso a cuidado infantil adecuado.

\section{Disponibilidad del cuidado infantil}

Si se dispusiera de cuidado infantil adecuado.... El problema es que en demasiados casos no existen arreglos satisfactorios, por lo cual la mujer no sólo se encuentra limitada en sus opciones de empleo y obligada a aceptar trabajos mal pagados (ya que éstos suelen ofrecer mayor flexibilidad) sino que sufre altos niveles de estrés, ansiedad y temor. En un estudio sobre la demanda y disponibilidad de cuidado infantil en 
la Ciudad de México, Kathryn Tolbert encontró que la crisis económica de 1982 hizo necesario que muchas mujeres volvieran a buscar empleo. Para resolver el problema del cuidado infantil, la mayoria de estas mujeres llevaban a sus hijos al trabajo, los dejaban con parientes o hermanos mayores, y, durante períodos breves, los dejaban solos (a veces atados a una cama para que no se lastimaran). ${ }^{10}$

La necesidad económica, la migración y los cambios en las normas sociales también suelen hacer que los parientes de la madre dejen de ser una fuente confiable de cuidado infantil. En la Ciudad de México Tolbert descubrió que "las abuelas, cuyo papel de cuidadoras de niños siempre ha sido importante en el mito y la realidad del Tercer Mundo, sólo están presentes en el 15\% de los hogares, mientras que otros parientes 0 familiares se hallan en el 10,8\% de los hogares"." La investigación ha demostrado que los arreglos para compartir el cuidado infantil entre redes de parientes o vecinos suelen ser reciprocos, lo cual impide que la mujer mantenga un trabajo de tiempo completo o con horarios fijos.

Otra importante falla del modelo de cuidado infantil que depende de familiares es el papel de los hermanos mayores, y especialmente las niñas y adolescentes, que deben dejar de asistir a la escuela para poder cuidar a los menores. Además de ser dudosa la calidad del cuidado que pueden proporcionar, en estos casos las jóvenes mismas quedan deprivadas de las oportunidades educativas que necesitan.

Obviamente, se necesita una opción mejor para la provisión de cuidado infantil, y ésta se encuentra sólo en la asignación de la responsabilidad a un sistema formal o informal de cuidado. Existen varios tipos de programas con este fin. desde instalaciones preescolares altamente organizadas hasta arreglos informales entre vecinos. Los programas de cuidado infantil también pueden operar dentro de cooperativas 0 fábricas, o pueden ser organizados por comunidades que requieren distintos niveles de participación y pago por parte de las madres.

Aunque las iniciativas recientes en cuidado infantil han logrado aumentar el número de niños que lo reciben, la cobertura total sigue siendo lamentablemente pequeña. Además, muchos de los nuevos programas se han orientado exclusivamente hacia el desarrollo del infante, sin tratar de responder a las necesidades de la madre. Existen centenares de pequeños proyectos experimentales, además de varias iniciativas a gran escala, que buscan promover el desarrollo de las capacidades del niño mediante la educación preescolar. A través de un proyecto de Servicios Integrados para el Desarrollo Infantil, por ejemplo, el gobierno de la India provee programas preesco- lares informales para más del 25\% de los niños de tres a seis años, y está extendiendo los servicios para incluir a niños más pequeños y a madres embarazadas y lactantes. En el Perú se espera ofrecer programas preescolares de desarrollo integral para el 25\% de los niños entre tres y cinco años de edad, y en Sri Lanka se busca cuidar a todos los niños de cinco años a través de la reducción de la edad de entrada a la escuela primaria, convirtiendo el primer año escolar en un tipo de jardin de infantes. ${ }^{12}$

Sin embargo, el alcance de estos programas suele estar limitado por la escasez de recursos humanos y económicos y la falta de apoyo gubernamental. Además, muchos de estos programas contienen serias desventajas para madres que trabajan: sólo aceptan niños con más de tres años de edad, en muchos casos durante sólo tres o cuatro horas por dia, y sólo durante los dias hábiles. Incluso cuando se dispone de servicios para infantes, suele no haber un sistema que permita que la mujer siga amamantando mientras trabaja. La falta de consideración por los obstáculos logísticos y económicos enfrentados por las madres que trabajan necesariamente limita el número de niños que estos programas pueden beneficiar. Además, muchos de los ambiciosos programas de desarrollo infantil que prometen atender a los requisitos de salud, nutrición y desarrollo del niño, en realidad apenas son capaces de proveer un servicio mínimo de guarderia.

De todos modos, existen algunos programas de cuidado infantil diseñados especificamente para responder a las necesidades de madres que trabajan, y se han identificado algunas estrategias eficaces. Además de los ejemplos descritos en esta edición de SEEDS, cabe mencionar los "jardin de infantes móviles" en la India: servicios de cuidado infantil situados en proyectos de construcción para las obreras con niños pequeños. En el ámbito rural también han aparecido cooperativas agricolas donde las mujeres cuidan a los niños en forma rotativa durante las temporadas de siembra y cosecha.

El modelo clásico para una instalación de cuidado infantil para fábricas, promovido por la Organización Internacional del Trabajo durante las primeras décadas de este siglo, sigue proporcionando cuidado en el sitio de trabajo para los hijos de obreros en algunas localidades. Sin embargo, el éxito de estas iniciativas ha sido limitado, ya que los gerentes suelen reemplazar obreras con obreros en vez de asumir los costos del cuidado infantil. Además, las mujeres suelen no estar dispuestas a someter sus niños a las penurias y peligros de los atestados transportes públicos que las llevan de ida y vuelta al trabajo. El tener que llevar a sus hijos lejos del hogar, incluso para obtener cuidado infantil de alta calidad, 
resulta demasiado inquietante para muchas mujeres de bajos ingresos. Durante su estudio en Lima, Perú, Anderson y Panzio encontraron que "la falta de la garantía de un nivel mínimo de seguridad se manifestaba también en la renuencia de las mujeres a mandar a sus hijos pequeños a un lugar lejano, cualquiera fuera la razón". Las mujeres prefieren no viajar en los autobuses municipales no sólo porque suelen ocurrir accidentes, sino porque "las mujeres que viajan cargadas con bolsas de mercancías, canastas para el mercado y niños pequeños no pueden defenderse" contra el robo y el acoso sexual. ${ }^{13}$

El transporte es, de hecho, un tema crítico para muchas madres que trabajan, ya que además de recibir sueldos muy bajos, suelen vivir lejos del sitio de empleo. La gran parte de la clase pobre urbana está concentrada en asentamientos situados en el periferio de grandes ciudades. Para los habitantes de estos barrios el transporte puede costar "entre la quinta y la tercera parte de un salario diario mínimo, y puede consumir entre tres y cinco horas por día". Esto significa que "la jornada laboral para la mujer que debe viajar de un lado de la ciudad a otro puede llegar a durar 13 o 14 horas cuando se incluye el tiempo de viaje". ${ }^{14}$ La mujer rural también suele vivir lejos de los campos que cultiva, y debe dedicar varias horas adicionales a caminar en búsqueda de agua, leña y forraje. En estos contextos, los programas que ofrecen cuidado infantil durante medio turno por día, aunque puedan responder a las necesidades educativas y nutritivas del niño, no pasan de ser una frustración adicional para la mayoría de las madres, ya que impiden que éstas mantengan empleos de tiempo completo.

En los proyectos descritos a continuación se puede apreciar cómo tres comunidades en distintas partes del mundo están enfrentando el problema del cuidado infantil y las madres que trabajan, a través de la participación local directa. Dos de los casos (Nepal y Ecuador) ilustran cómo el concepto de "cuidado en el hogar" está operando junto con métodos más tradicionales basados en centros infantiles. Es evidente que los sistemas de cuidado en el hogar, así como el modelo operado y apoyado por la comunidad en Etiopia, representan mejores maneras de satisfacer las necesidades de la mujer, no sólo porque proveen cuidado de alta calidad durante sus horas de trabajo, sino porque hacen posible que se ayude a sí misma, a sus hijos y a su comunidad. Para las mujeres, estos programas son "semillas del cambio social", observa Tolbert en base a proyectos en México, "... ponen en marcha un proceso que presta dignidad a la necesidad o el deseo de trabajar, legitiman el interés de la comunidad por el bienestar de sus hijos, y permiten que las mujeres se unan en base a las mismas inquietudes para formar, a menudo por la primera vez en sus vidas, asociaciones que van más allá del núcleo familiar". ${ }^{15}$

\section{Proveedoras de cuidado infantil}

Además de ofrecer cuidado infantil conveniente, económico y de buena calidad a mujeres que trabajan, estos proyectos demuestran que el cuidado infantil basado en la comunidad también puede proveer oportunidades de empleo para mujeres locales. La posibilidad de trabajar como proveedora de cuidado infantil no sólo representa una fuente de ingresos para muchas mujeres pobres; también les ofrece la oportunidad de recibir entrenamiento, desarrollar capacidades gerenciales y elevar su posición dentro de la comunidad. Por otro lado, puede ser que las cuidadoras infantiles, incluso cuando hayan sido capacitadas, sigan ganando menos que otros trabajadores con habilidades comparables. Teniendo en cuenta que las mujeres siguen ganando, en promedio, dos tercios de lo que ganan los varones, no ha de sorprendernos que los sueldos de las responsables de cuidar a sus niños sean sumamente bajos. En Ecuador, por ejemplo, las maestras preescolares capacitadas ganan aproximadamente el $40 \%$ del salario de una maestra de escuela primaria, mientras que en Estados Unidos, un estudio de 1989 demostró que las proveedoras de cuidado infantil reciben, en promedio, el 30\% del salario de una típica maestra de escuela primaria. ${ }^{16}$ Estas diferencias pueden contribuir a un alto nivel de rotación del personal, ya que muchas cuidadoras recién "capacitadas" podrán encontrar trabajos mejor pagados.

Aunque siga estando de moda debatir si deberían o no trabajar las mujeres que tienen hijos, y especialmente hijos pequeños, lo cierto es que el número de mujeres que lo hace es cada vez más grande. Es preciso reconocer esta realidad y desarrollar nuevas y mejores opciones para la provisión de cuidado infantil apropiado para mujeres que trabajan.

Dichas opciones también deberán ofrecer un ambiente sano y seguro para los niños, en el cual se pueda satisfacer los requerimientos de su desarrollo. Se espera que los ejemplos a continuación proporcionen una idea de lo posible, además de indicar lo que queda por hacer. 


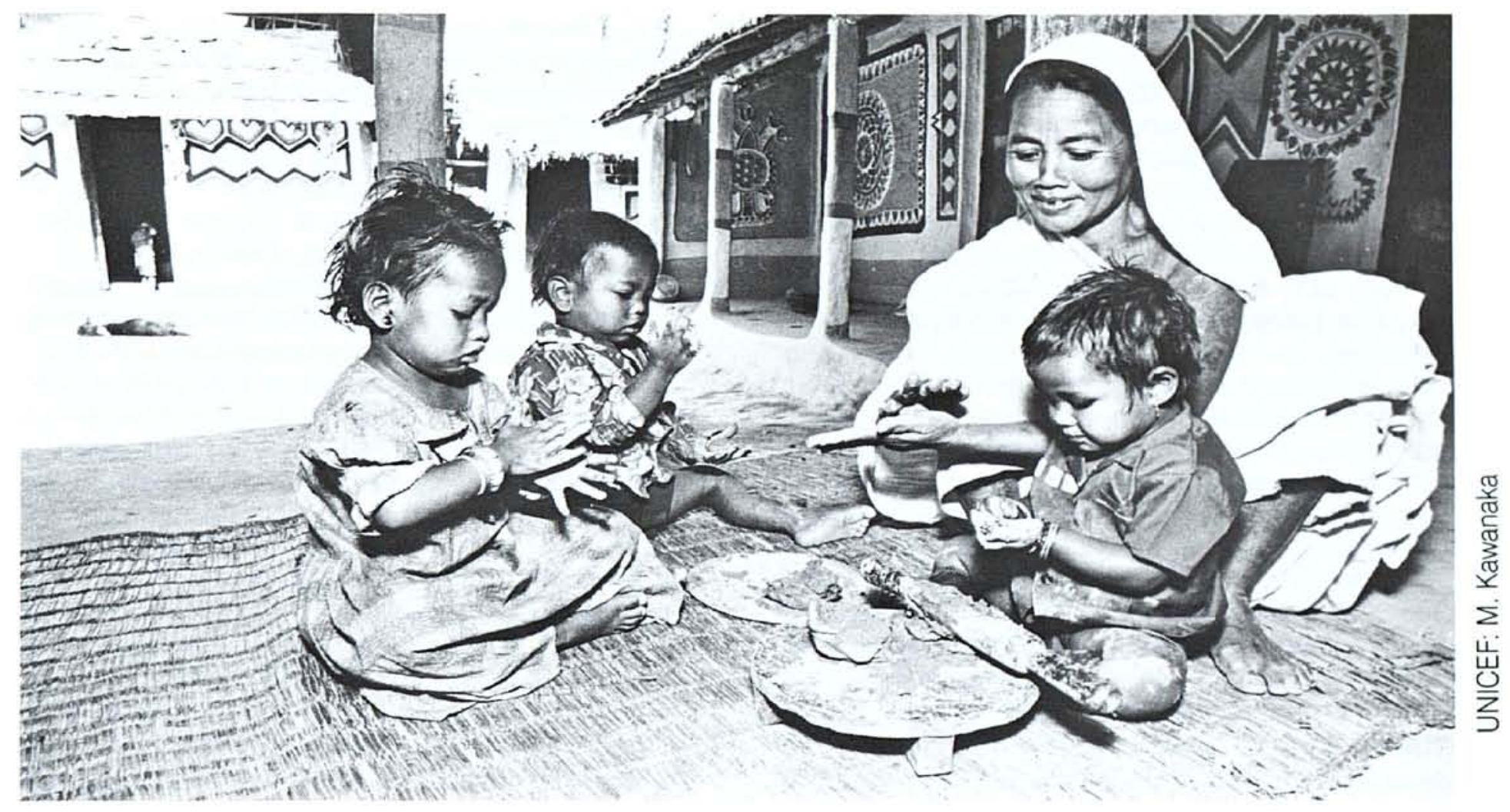

\section{Nepal: Proyecto Punto de Entrada}

\section{Trasfondo}

Nepal es un pais de gran diversidad. Situado entre China e India, su terreno desciende desde las famosas cumbres Himalayas, pasa por sierras medianas y termina en las llanuras subtropicales conocidas como el terai. El 94\% de la población de Nepal vive en regiones rurales, la mitad de las cuales no son accesibles por caminos. La gran variedad geográfica del país se ve reflejada en la multiplicidad de grupos étnicos y prácticas culturales.

Nepal tiene unos 18 millones de habitantes, ocho millones de los cuales tienen menos de 15 años. Predominan las familias grandes, con un promedio mínimo de seis hijos. La importancia y flexibilidad de la familia representan un punto de convergencia entre los distintos grupos étnicos del país. Pero en casi todos los casos, las familias están sintiendo las presiones causadas por la creciente escasez de terrenos familiares que han sido divididos y subdivididos con cada generación, a tal punto que ya no dan abasto.

Una multitud de presiones ecológicas y de población hacen cada vez más difícil la vida en Nepal. Actualmente Nepal figura como uno de los países más pobres del mundo (según el Informe de Desarrollo Mundial de 1985, sólo tres otros países registraron un producto bruto nacional menor al de Nepal). Casi todas las mejoras en la economia nepalesa han sido eclipsadas por el crecimiento de la población, el cual alcanza el $2,99 \%$ por año y sigue aumentando. Pese a varias inversiones en el desarrollo agrícola, la población rural de Nepal está padeciendo un proceso de empobrecimiento que se manifiesta sobre todo en las deficiencias nutricionales que amenazan a mujeres y niños.

\section{La vida y el trabajo de las mujeres}

La gran mayoría de los nepaleses son agricultores de subsistencia. La finca o granja familiar provee cerca del $80 \%$ de los ingresos anuales del hogar promedio. La división del trabajo da por sentado que la mujer carga con la mayoria de las tareas y que desempeña múltiples papeles. Según estudios que comparan la distribución de tiempo laboral, la mujer nepalesa debe trabajar 11 horas por dia sólo para mantener el nivel de subsistencia de la familia, mientras que los varones sólo contribuyen unas 6 horas por día al trabajo agricola familiar.

Según los Informes sobre el Estado de la Mujer editados por la Universidad de Tribhuban en 1981, en Nepal la opinión de la mujer tiende a predominar en las decisiones relativas a la agricultura y los asuntos del hogar. El 98\% de las mujeres consideradas como "económicamente activas" trabajan en agricultura, ya que los bajos niveles de educación siguen obrando en contra del empleo de mujeres en el sector formal. 
Además de contribuir a la agricultura familiar y el mantenimiento del hogar, las mujeres complementan sus ingresos con actividades económicas "informales", como ser el comercio a pequeña escala, la mercadotecnia y las artesanías. Sin embargo, la cantidad de tiempo que las mujeres rurales disponen para actividades de mayor potencial económico queda limitada por el tiempo que necesitan para cuidar a los niños y conseguir agua, comida y combustible para la familia.

En su papel de madre la mujer juega un papel crítico en el desarrollo de sus hijos, pero su capacidad para nutrirlos y estimularlos suele estar limitada por condiciones sociales que le impiden acceso a alimentos, servicios, recursos e información. Además, la carga laboral de las mujeres impide que tengan tiempo para estar con sus hijos. Con cada año que pasa, por ejemplo, es necesario caminar más lejos para llegar a los campos y montes donde todavía se encuentra leña y forraje, lo cual reduce aún más el tiempo que las madres pueden dedicar a sus hijos.

Cerca del $40 \%$ de los niños nepaleses dejan de asistir a la escuela durante el primer año, y entre los que permanecen, el $25 \%$ encuentran tantas dificultades que deben repetir el primer grado. El acceso de las niñas y las mujeres a las oportunidades educativas es particularmente limitado, por lo cual el 82\% de las mujeres nepalesas son analfabetas en la actualidad. Obviamente, estos límites impiden que la mujer adquiera los conocimientos necesarios para participar en el proceso de desarrollo. La probabilidad de que las niñas asistan a la escuela es mínima cuando se supone que deben ayudar en las tareas domésticas, y peor aún si tienen que encargarse del cuidado infantil. Combinada con una desconfianza general en cuanto al sistema de educación, esta realidad tiene como consecuencia un nivel de matriculación de niñas en la escuela primaria de sólo el 30\%. En algunos distritos sólo el 13\% de las niñas están matriculadas, y la concurrencia de éstas es 50\% menor a la de los varones.

\section{Cuidado infantil y desarrollo}

La mayoría de los nacimientos en Nepal ocurren en el hogar, con la asistencia de una partera tradicional. El bebé suele pasar los primeros meses de vida con la madre. Hasta los seis meses de edad, las mujeres cargan con el bebé o lo llevan en una canasta. Las niños suelen recibir mucho afecto. Los abuelos pasan muchas horas jugando con ellos, y siempre están rodeados por familiares. Cabe notar que esta atención incluye mucho contacto físico, ya que la calidad del intercambio social temprano es fundamental al desarrollo de cualquier niño.
Una vez que el infante empieza a gatear es más probable que la madre vuelva a ocuparse con tareas agrícolas y que lo deje en manos de otros familiares. La adquisición de la capacidad de exploración expone el infante a un medio ambiente altamente contaminado, donde las enfermedades se suman a su precario estado nutricional para perjudicar su desarrollo.

Muchos niños nepaleses sufren severas carencias en sus necesidades básicas, y uno de cada seis muere antes de cumplir cinco años. Los altos índices de mortalidad infantil (113) y entre niños mayores de cinco años (165) no sólo ilustran los efectos de la pobreza cíclica, sino que dan una idea de la precaria salud de los que logran sobrevivir. Los datos relativos a la relación entre peso y edad recolectados por el Estudio Nacional de Nutrición indican que dos tercios de los niños nepaleses menores de seis años están desnutridos, y un 5\% adicional se encuentran gravemente afectados por la desnutrición.

Una vez que el niño aprende a caminar se considera que es lo suficientemente grande como para dejarlo con una hermana mayor. Una niña de cinco años, o incluso menos, puede estar encargada de cuidar a criaturas de uno o dos años. Desde este punto en adelante, el niño recibe información sobre el mundo principalmente a través de otros niños, y en vez de aprender por instrucción directa tiende a hacerlo por imitación. Los padres, sin embargo, se encargan de la higiene, los alimentos y las cualidades morales del niño.

\section{Identificando las necesidades}

En Nepal, la mayoria de los niños que sobreviven los primeros años de vida siguen estando expuestos a las mismas condiciones de pobreza que amenazan la vida e perjudican el desarrollo. En consecuencia, los programas de desarrollo infantil deben estar fuertemente orientados hacia salud, nutrición, sanidad y educación para los padres. Para que la perspectiva de desarrollo complemente el énfasis en supervivencia, también se incluye un componente psicosocial que trata de preparar al niño para una participación positiva en su sociedad.

El diseño de programas de desarrollo infanth en Nepal también debe ser sensible a las presiones que acompañan el doble papel de las mujeres: más allá de sus agotadoras responsabilidades como madres, también deben satisfacer los requerimientos materiales mínimos de su familia. El desafío, por lo tanto, reside en desarrollar programas que responden simultáneamente a las necesidades entrelazadas de madres y niños. La falta de acceso de la mujer a la educación y la información, así como su falta de tiempo, también deben ser consideradas. Los maridos y 
el resto de la comunidad también deben participar, ya que la educación y la información no deben estar dirigidas sólo a las madres.

En Nepal la instrucción previa al nivel primario no figura dentro del sistema formal de educación, por lo cual existe muy poca pericia sobre el desarrollo infantil. La Organización Nepalesa del Niño opera centros que proveen educación preeșcolar y cuidado infantil para unos 4.000 niños, pero los centros están situados en las sedes de distritos y sólo sirven al personal del gobierno y a varios residentes locales. Aunque en Katmandú, la capital nepalesa, se dispone de varios centros preescolares privados, en las regiones rurales casi no existen instalaciones de cuidado infantil.

\section{Tomando acción}

El programa infantil descrito a continuación ha sido desarrollado como parte integral del proyecto Créditos para la Producción entre Mujeres Rurales (conocido por su sigla en inglés, PCRW), una iniciativa apoyada por UNICEF. Administrado por la Sección de Desarrollo de la Mujer (WDS) del Ministerio de Panchayats (la unidad de gobierno local en el Nepal) y Desarrollo Local, el proyecto PCRW provee apoyo para una variedad de actividades de crédito y desarrollo comunitario realizadas por mujeres rurales. En términos generales, el proyecto PCRW refleja la estrategia de servicios básicos de UNICEF: se debe atender al niño dentro del contexto de su comunidad, buscando cambios sociales y ambientales que beneficien a todos y que mejoren la salud y el desarrollo integral del niño.

El proyecto PCRW funciona a través de promotores locales que asisten a mujeres rurales de bajos ingresos, ayudándoles a conseguir créditos disponibles a través de bancos nacionales. Las mujeres usan los créditos para financiar proyectos agrícolas, servicios, e industrias de pequeña escala, actividades que se prestan a la generación de ingresos porque muchas mujeres ya las están realizando. El componente de desarrollo comunitario del proyecto permite que las mujeres participen en la definición de problemas locales y la implementación de soluciones. Las actividades varian de acuerdo a las prioridades y los recursos disponibles en cada localidad.

Los componentes económicos y de desarrollo comunitario del PCRW se complementan, más allá de su valor inherente, porque la capacidad de una mujer de aprovechar oportunidades económicas suele depender de la disponibilidad de servicios provistos por iniciativas de desarrollo comunitario. $Y$ dado que el enfoque de las iniciativas de desarrollo comunitario ha sido las necesidades de la mujer, se ha dado prioridad a proyectos que reducen la cantidad de tiempo que ésta requiere para completar sus tareas cotidianas. La provisión de fuentes de agua cercanas a la aldea, moledoras para procesar granos y aceite, e instalaciones para el cuidado infantil son algunos ejemplos de este enfoque.

En el diseño original del proyecto, el

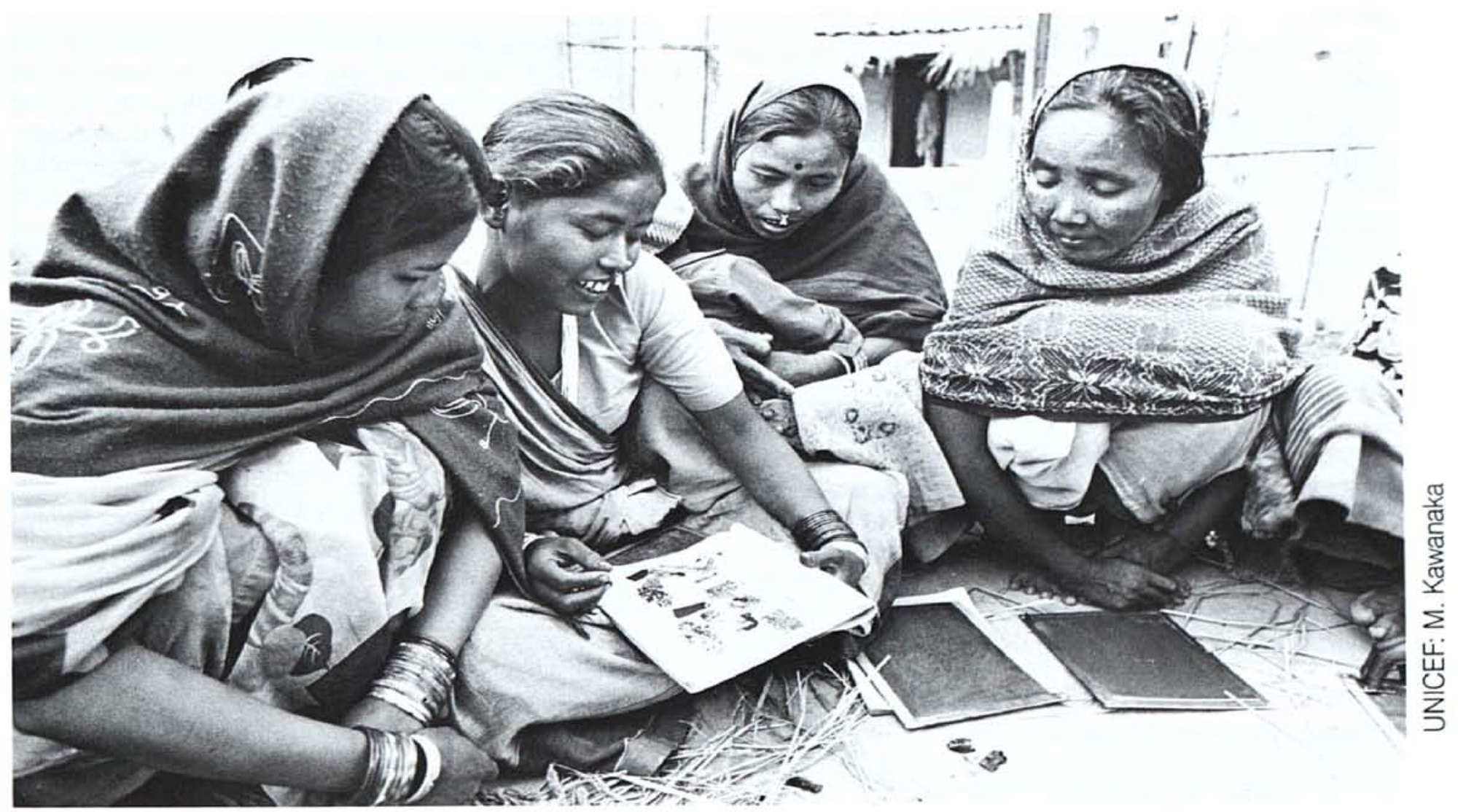


cuidado infantil figuraba como sólo un pequeño componente en el énfasis de desarrollo comunitario del PCRW, ya que el objetivo principal era ahorrarle tiempo a las mujeres para que pudieran abordar actividades de generación de ingresos. Pero en la práctica, la mayoría de los promotores indicaron que el cuidado infantil era la prioridad principal de las mujeres, por lo cual llegó a ser un aspecto central del conjunto de actividades entrelazadas del PCRW.

La experiencia ha demostrado que las iniciativas de cuidado infantil que se emprenden como parte de un proyecto integral de desarrollo comunitario tienen una mejor posibilidad de generar el apoyo y la cooperación de varios sectores. Sin embargo, el proceso mediante el cual se motiva la participación concreta de los padres y se establece un sistema verdaderamente comunitario suele ser lento y complejo. También resulta dificil que una comunidad que funciona en los márgenes de la economía formal se haga cargo de los gastos de administración de los centros de cuidado infantil.

Los planificadores del PCRW se dieron cuenta de que en Nepal no se podria depender exclusivamente del modelo de cuidado infantil basado en centros. Con la ayuda de UNICEF, diseñaron varias estrategias de bajo costo basadas en la comunidad y capaces de alcanzar un mayor número de niños.

- Programas para niños de tres años de edad para abajo, ubicados en casas particulares, y operados por madres locales en un sistema rotativo.

- Centros comunitarios de cuidado infantil para niños de tres a seis años de edad.

- Clases de educación para padres, realizadas en centros comunitarios o de cuidado infantil, que cubren temas desde la atención prenatal hasta las necesidades de niños en edad escolar.

- Un programa de "Niño a niño" que fomenta la capacidad de los niños mayores de promover la salud, el bienestar y el desarrollo de los menores.

Aunque cada una de estas estrategias ha sido implementada hasta cierto punto, es evidente que los programas basados en hogares han sido los que satisfacen mejor las necesidades inmediatas de cuidado infantil de las mujeres. Dichos programas proporcionan un ambiente sano y seguro para los niños, y para las mujeres que los cuidan, ofrecen la posibilidad de adquirir nuevas capacidades y fortalecer su sentido de confianza.

\section{"Punto de entrada", un programa basado en el hogar}

El programa praveshdwar (palabra nepa- lesa que significa "punto de entrada" o puerta principal de un lugar grande e importante), es sin duda el componente más inovador del proyecto. Reconociendo el papel central de la mujer en la familia, el programa "punto de entrada" se enfoca en la madre y emplea al hogar rural como base de actividades.

Las madres que desean participar en el programa se organizan en grupos, tipicamente de seis miembros. Como en casi todas las actividades del PCRW, el grupo representa el punto de enfoque para la acción. Antes de que puedan recibir entrenamiento, el grupo y la comunidad deben conseguir un local con baño y cocina. En algunos casos la comunidad ha conseguido un cuarto para el programa, mientras que en las regiones donde el clima es más cálido, se han construido simples albergues con este fin. Pero en la mayoria de los casos las madres administran el programa de modo rotativo en sus propias casas, cuidando a niños de tres a seis años de edad, o en un salón proporcionado por una familia que no lo necesita. Los miembros del grupo establecen un horario según sus propias necesidades, y se reúnen una vez por semana para asegurar que el programa esté funcionando bien.

Cada grupo recibe un cajón de lata con varios materiales básicos. Estos incluyen implementos para cocinar, platos, tazas, un balde, una jarra, materiales de higiene personal, una alfombra, dos muñecas, tres títeres, una pelota y un tambor. Además de los materiales básicos, los grupos pueden recibir materiales recreativos que ayudan a introducir conceptos específicos como la forma, el color, las partes del cuerpo, y los animales domésticos. Actualmente se dispone de nueve paquetes de juegos distintos, por lo cual grupos vecinos suelen intercambiarlos con el propósito de exponer los niños a una mayor variedad de juguetes y materiales. También se utilizan varios juguetes de bambú, hechos a mano por los padres.

Dado que la mayoria de las madres son analfabetas, se utiliza un cuadro ilustrado para indicar el horario diario de actividades. Los niños juegan individualmente con materiales que les ayudan a aprender una variedad de conceptos y habilidades, y participan además en simples juegos de grupo que enfatizan la facultad creadora sin competencia. Las cuidadoras ponen un fuerte énfasis en la higiene y el uso del inodoro, y cada día las madres contribuyen alimentos para preparar una comida nutritiva.

Sri Maya es una madre que vive en las sierras nepalesas y participa en un programa "punto de entrada". Esta mañana, mientras espera la llegada de los niños, está preparando un grupo de juguetes de bambú hecho por varios padres 


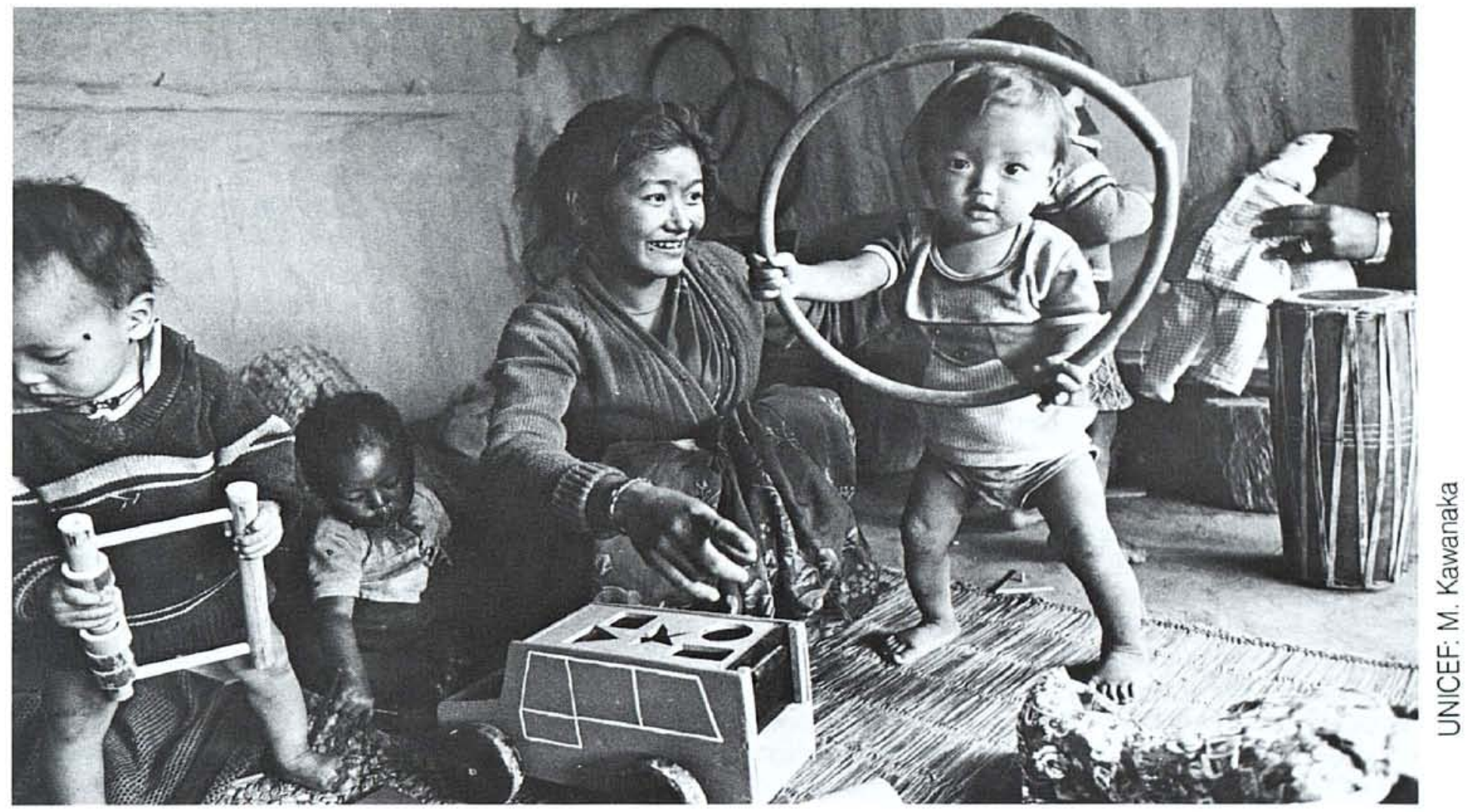

locales. Al rato escucha risa y voces en la calle. Los otros niños han empezado a llegar con sus madres, y quieren saber cuál de los juegos van a jugar. Sri Maya recibe a cada madre con un gesto formal de namaste (el saludo tradicional en Nepal) y le da un abrazo a cada uno de los niños.

Luego las madres charlan brevemente sobre el clima: parece que la temporada de lluvia está por llegar y es preciso terminar con la siem. bra. Es posible que las madres lleguen un poco tarde a buscar a sus chicos, pero no hay problema, porque el hecho de manejar el programa entre si les permite ser flexibles.

Sri Maya primero ayuda a que los niños se laven las manos y la cara, y luego los lleva afuera para participar en un juego nuevo en el cual bailan al compás de un ritmo que ella marca con un tambor. Cuando Sri Maya deja de tocar, los niños deben coger todas las mazorcas de maíz que puedan y colocarlas dentro de un gran aro de caña. Los niños tardan un rato en comprender el concepto, pero el hijo de Sri Maya, que tiene cuatro años, le da una mano a los más pequeños.

Uno de los aspectos notables de la situación es la intensidad de la atención que Sri Maya le presta a los niños. Incluso cuando está preparando el almuerzo, Sri Maya sigue conversando con ellos, comentando sobre el juego de estaquillas que uno acaba de completar, simpatizando con otro que tiene una muñeca enferma, y sugiriendo dónde algún otro podría encontrar la pelota. El día transcurre en una serie de can- ciones, cuentos y juegos; Sri Maya siempre está disponible para estimular la exploración, compartir en la risa y consolar el llanto ocasional.

Pero el programa "punto de entrada" no sólo beneficia a los niños. Los conocimientos y la confianza que las madres adquieren en su nuevo papel de cuidadoras suele cambiar la calidad de la relación que mantienen con sus propios hijos. Las madres también encuentran que aunque están dedicando un día por semana al cuidado de un grupo de niños, este arreglo termina por darles más tiempo para otras actividades, incluso para la generación de ingresos.

"Al principio yo pensé que este programa interferiria con mi trabajo, pero ahora Naresh no parece enfermarse tanto como antes, cuando yo solia tener que quedarme en casa porque él estaba tan enfermo que no me atrevia a dejarlo. Antes, incluso cuando Naresh estaba sano, yo me preocupaba y trataba de volver a casa al mediodía para asegurarme de que estuviera bien, aunque el viaje de ida y vuelta a mis campos demoraba una hora y media... Y ahora Sumita está contenta porque puede asistir a la escuela en vez de quedarse en casa todo el día para cuidarlo".

Al trabajar de modo cooperativo a lo largo del año, las madres aprenden técnicas gerenciales básicas y fortalecen su sentido de responsabilidad colectiva. Las capacidades y la 
confianza que adquieren se manifiestan posteriormente en otras actividades de desarrollo comunitario y generación de ingresos. $Y$ el proceso suele ser recíproco: los grupos que participan en proyectos de generación de ingresos en muchos casos terminan por instalar sus propios programas de cuidado infantil en el hogar. En mayo de 1989 se habian formado 54 grupos en 11 distritos de Nepal, y 50 grupos de crédito ya establecidos se estaban preparando para instalar programas de cuidado infantil ni bien pudieran recibir el entrenamiento necesario.

\section{Entrenamiento, supervisión y evaluación}

Como se señaló anteriormente, existe muy poco conocimiento sobre el desarrollo infantil en Nepal. En 1986 UNICEF empezó a responder a este problema con la creación de los Servicios Nacionales de Desarrollo Infantil Seto Gurans. Estos servicios han asumido el papel principal en la provisión de entrenamiento para el programa de desarrollo infantil del PCRW.

El entrenamiento para los programas basados en el hogar dura cuatro días y se realiza en la localidad del futuro programa. La metodología para el entrenamiento fue elaborada inicialmente por el personal de la Sección Mujer y Desarrollo (WDS, entidad que administra el proyecto PCRW), a través de discusiones y actividades con grupos de mujeres en una pequeña aldea nepalesa.
Desde entonces el entrenamiento ha sido modificado continuamente en respuesta a las necesidades locales. Además de los temas generales de desarrollo infantil, el entrenamiento incluye unidades sobre salud, nutrición e higiene (un tema especialmente importante en un país donde el $90 \%$ de la población no tiene acceso a instalaciones sanitarias). En la unidad sobre nutrición, las madres aprenden a controlar el ritmo de crecimiento infantil, a practicar los elementos básicos de la nutrición, y a preparar comidas nutritivas usando sólo aquellos ingredientes que se cultivan en la localidad.

Mientras que las madres están en el curso de entrenamiento, los padres aprenden a fabricar los juguetes que se emplearán en el programa. Todos los juguetes se fabrican con bambú, un material ampliamente disponible en todo el país. Luego las mujeres aprenden a usar los juguetes en actividades recreativas diseñadas para introducir conceptos y desarrollar capacidades entre los niños. El entrenamiento enfatiza la importancia del papel de "maestra" de las madres, y trata de hacer que sientan confianza en su capacidad de administrar el programa. Aunque se discuten varias cuestiones prácticas en términos generales, las decisiones diarias relativas al manejo del programa se dejan en manos de las mujeres.

Virtualmente todas las madres en los programas "punto de entrada" son analfabetas, por

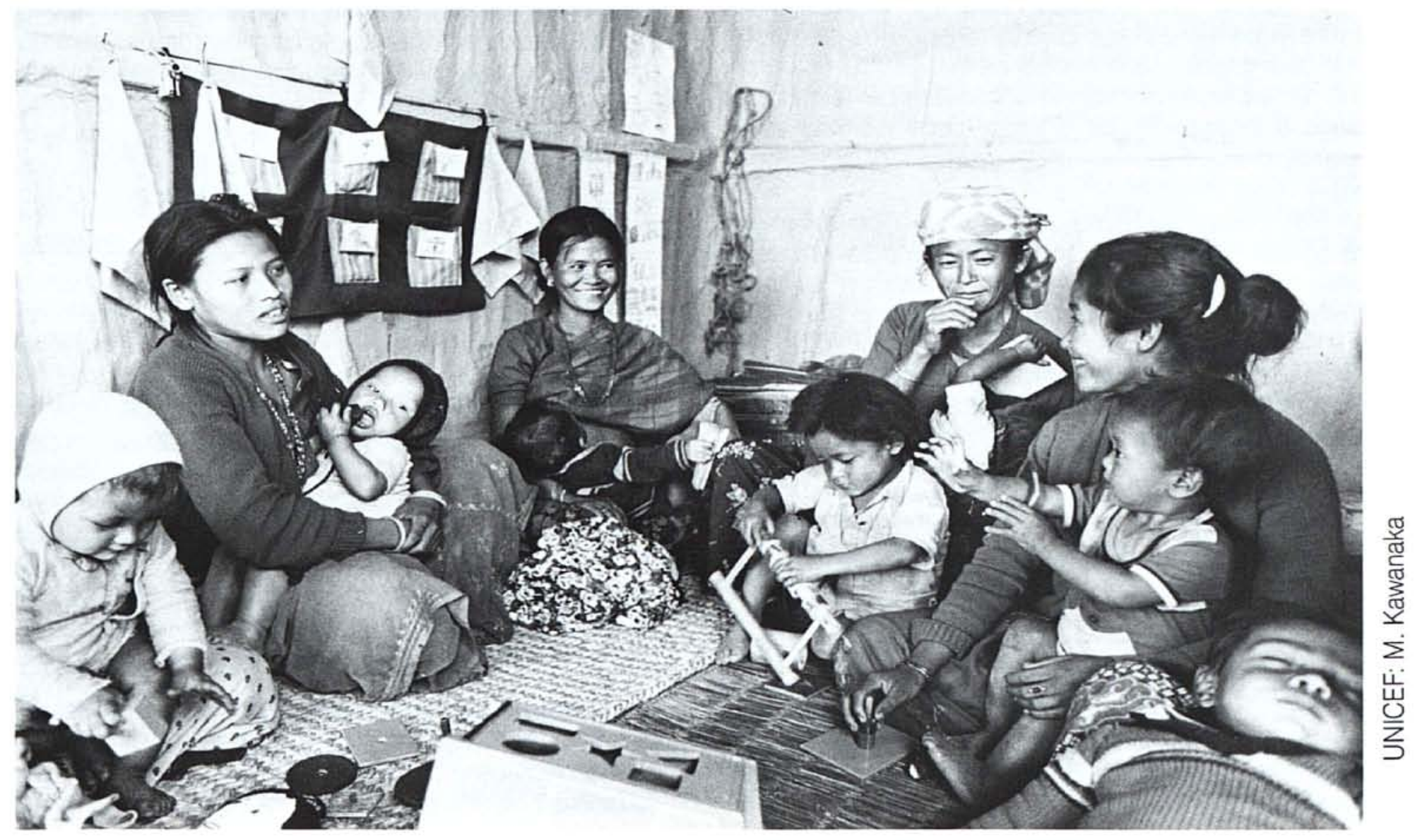


lo cual se dedica bastante tiempo a explicar el uso del inventario ilustrado y la agenda diaria que vienen con los materiales básicos. A medida que componen letras para las canciones y deciden cómo quieren organizar el horario diario, las madres suelen sorprenderse al ver que sus opiniones no sólo se solicitan, sino que el grupo las incorpora e utiliza. Cualquier observador de estas sesiones no puede dejar de concluir que realmente se trata de un programa por y para las mujeres. Inicialmente las madres tienden a ser tímidas y reservadas, pero al poco tiempo todas se empiezan a relajar, riéndose y participando en los juegos. Es casi palpable el crecimiento de la confianza y dignidad del grupo a lo largo del entrenamiento, aunque las mujeres tampoco dejan de divertirse.

El programa en Nepal también incluye centros de cuidado infantil que sirven a grupos de entre 25 y 30 niños de tres a seis años de edad. En la actualidad existen unos 60 centros de cuidado infantil que sirven a unos 1.800 niños en 32 de los 75 distritos de Nepal. Bajo la supervisión de comités para la administración del cuidado infantil comunitario, una maestra y una asistente elegidas por la comunidad operan los centros luego de ser capacitadas durante un mes en Seto Gurans. Aunque se supone que las mujeres que reciben entrenamiento deben dejar a sus hijos en casa, en realidad los cursos suelen incluir media docena de infantes o niños demasiado enfermos como para estar solos. En situaciones donde una mujer vive sola y no tiene quien la ayude con sus hijos, se le permite que los traiga a las sesiones. En contraste con casi todos los programas de entrenamiento en Nepal (incluso aquellos que supuestamente se orientan hacia las necesidades de las mujeres y los niños), en Seto Gurans se insiste en acomodar a las mujeres que necesitan traer a sus hijos. Aunque esto suele imponer una carga adicional sobre el personal de entrenamiento, siempre ha sido posible hacerlo, y el personal jamás se ha opuesto a esta práctica.

El personal de la Sección Mujer y Desarrollo está dividido en dos grupos principales: 1) personal local (compuesto de funcionarias y asistentes en desarrollo) que facilita el diseño y la implementación de actividades económicas y proyectos de desarrollo comunitario, y 2) personal central que provee el apoyo técnico, logístico y administrativo requerido para el trabajo local. El entrenamiento de ambos tipos de personal es esencial al programa y, como en otras actividades del PCRW, está enfocado en la dinámica del grupo. Antes de comenzar el entrenamiento en si se trabaja extensamente en la formación de una conciencia de grupo. El personal local asume el papel crítico de movilizar a los grupos dentro de cada aldea. Uno de los aspectos sobresalientes del entrenamiento del personal local del PCRW es la prioridad que se le otorga al trato respetuoso, el fomento de confianza, y la motivación de las mujeres rurales. Estas prioridades se han convertido en la base fundamental de todo el entrenamiento a nivel de aldea del PCRW. Una vez que se establece un programa, el personal local sigue apoyando, supervisando y ofreciendo entrenamiento adicional a las participantes; dichos factores son quizás los que más contribuyen al éxito sostenido del programa.

\section{Las virtudes del programa}

El programa de cuidado infantil tiene varias virtudes entrelazadas que surgen de metas y actividades elaboradas en base a la familia y la comunidad, y con el propósito de responder a las necesidades de madres que trabajan. Estas cualidades son especialmente apreciables en los programas "punto de entrada". En vez de ser prescripciones rigidas impuestas desde afuera, estos programas contienen una flexibilidad inherente que permite que las familias y las comunidades decidan por su cuenta cómo los quieren manejar. $\mathrm{El}$ proceso de planificación empieza con las mujeres de la aldea y responde a sus perspectivas del problema. La planificación, administración, supervisión y el apoyo funcionan de un modo decididamente descentralizado.

Otra virtud de las iniciativas en desarrollo infantil ha sido su integración en otras actividades económicas y de desarrollo comunitario, lo cual ha motivado la participación de la comunidad entera. Además, los programas han hecho que se reconozca la compleja relación entre el trabajo de la mujer, el acceso al crédito, y los programas de cuidado y desarrollo infantil.

El programa también se ha destacado por su reconocimiento de la importancia critica de la dinámica de grupo. La formación de grupos en base a propósitos comunes, como ser la obtención de crédito o la instalación de un programa de cuidado infantil en el hogar, es una de las maneras fundamentales de fomentar la confianza que el individuo requiere para mejorar su propia vida. El apoyo mutuo que las mujeres se ofrecen en este contexto también ayuda a mejorar el bienestar de sus hijos. Lo importante es crear programas en base a las capacidades existentes de las mujeres, sus familias y sus comunidades, en vez de suponer que éstos no tienen nada que aportar.

Este reconocimiento de las capacidades existentes también es indispensable en el desarrollo de un programa de entrenamiento que fomenta el respeto por las prácticas y conocimientos de los estudiantes. Asimismo, los materiales de entrenamiento, y los que se utilizan en el programa, son pertinentes, atractivos, prácticos y apropiados para el nivel educativo de las partici- 
pantes. El diseño de los materiales enfatiza las relaciones entre salud, nutrición y estímulo en el desarrollo infantil, y esta filosofía integral se ve reflejada en todos los aspectos del programa.

La colaboración entre varias agencias, y especialmente la Sección Mujer y Desarrollo, UNICEF y Seto Gurans, también ha contribuido al éxito del programa en todos los niveles. Más allá de proveer apoyo económico y asistencia práctica, UNICEF ha jugado un importante papel de apoyo en la conceptualización y el desarrollo de estrategias alternativas y complementarias.

Los servicios de Seto Gurans han proporcionado apoyo y asistencia técnica indispensable en la elaboración de metodologias de entrenamiento, sistemas de supervisión y otros materiales. Al nivel de distrito se han enfatizado los lazos con los servicios de salud del gobierno y el componente de saiud comunitaria del PCRW.

\section{Problemas}

La dispersión de la población, las dificultades del terreno, y la falta de caminos transitables crean serios obstáculos para las iniciativas que buscan alcanzar a los niños de Nepal, y subrayan la importancia de la descentralización de los sistemas de supervisión. La dependencia creada por el financiamiento exterior representa otro serio problema. Aunque se reconoce la importancia de asegurar la autosuficiencia económica, se ha logrado relativamente poco al respecto, y otras agencias interesadas en proyec- tos similares deberian prepararse para estas dificultades.

\section{Resultados entre las mujeres, los niños y la comunidad}

Una variedad de datos anecdóticos indican que el programa está logrando un notable impacto positivo. Es evidente que los programas de cuidado y educación infantil benefician a las mujeres al darles más tiempo para otras actividades. La Jefa de la división de nutrición y cuidado infantil de la Sección Mujer y Desarrollo dice que cuando visita centros de cuidado infantil y grupos "punto de entrada", el comentario que escucha con mayor frecuencia es "ahora estamos mentalmente libres".

Es evidente que la participación de las mujeres en los programas basados en el hogar ha sido tan importante para su desarrollo personal como cualquier otra actividad iniciada por el PCRW. En base a la confianza que han adquirido en su papel de "maestras", algunas mujeres han empezado a surgir como lideres en la comunidad, empleando sus nuevas capacidades de administración y organización en una variedad de actividades.

También se puede apreciar la diferencia entre los niños que están asistiendo a un programa basado en el hogar o un centro de cuidado infantil, y los de otras aldeas donde no existe ningún tipo de actividades para el desar-

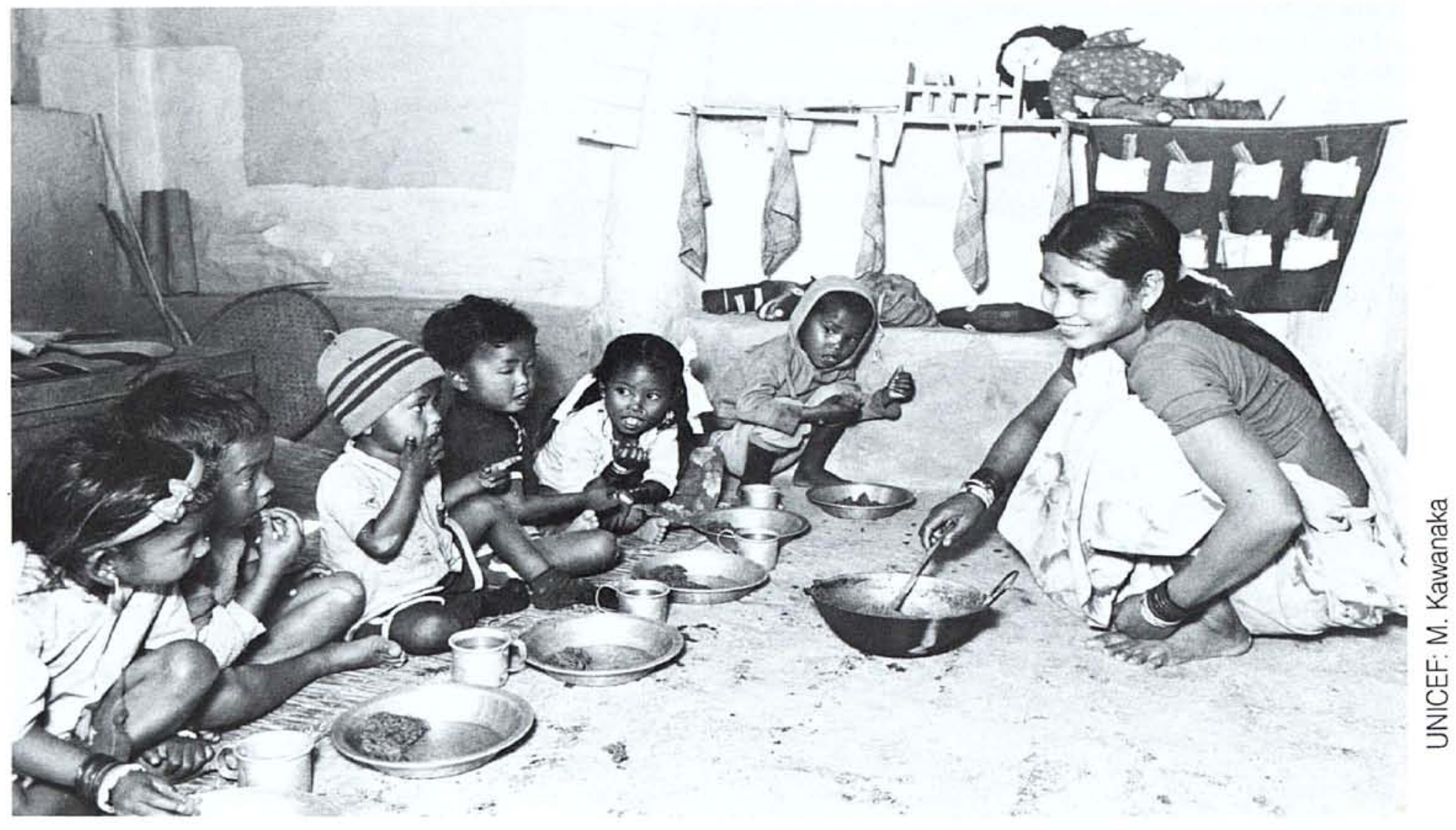


rollo infantil. El contraste se puede ver en la apariencia general de los niños, en su estado nutricional y de salud y, de igual importancia, en su sensibilidad, sociabilidad y sentido de curiosidad. Según una de las supervisoras, "Se nota la diferencia. Se les ve la chispa. Y existe un sentido de esperanza y felicidad". Un niño de tres años lo expresa así: "Es divertido. Mi mamá sabe jugar todos estos juegos".

La supervisora también señala que "el impacto del programa sobre la salud, la nutrición y el desempeño escolar de los niños es extraordinario". Informes sometidos recientemente por funcionarios del desarrollo de la mujer en los distritos de Kotari, Sivangunj y Tharpu indican que la totalidad de los niños que reciben cuidado infantil en estas regiones pasan a la escuela primaria, mientras que antes sólo lo hacía un tercio. Mikana K.C., una de las supervisoras con mayor antigüedad, añade que "Los niños que han estado en un programa 'punto de entrada' o un centro de cuidado infantil no dejan de asistir a la escuela y no repiten cursos como los otros niños".

"La niñez es la primera etapa de la vida, asi como el cimiento es la base de una casa. La casa sólo puede estar bien construida si el cimiento es sólido. Asimismo, si el niño ha de prosperar y ser fuerte, debemos asegurar que su niñez sea positiva. Por ser tan difícil la vida para casi todos nosotros, no es fácil ocuparnos debidamente de la salud y el futuro de los niños, pero los programas de desarrollo infantil han creado nuevas avenidas. A veces nos cuesta proveer sólo dos comidas por día, pero creemos que podemos iluminar un poco el futuro de nuestros niños, como uno que llega a su destino con una antorcha en la oscuridad... yo creo que alcanzaremos nuestra meta a través de nuestros propios pasos...."

Radha, una madre de Utter Par, Surkhet, Nepal

\section{Mirando hacia el futuro}

Al anticipar el crecimiento del programa de desarrollo infantil, se deben considerar los problemas de duplicación y sustentabilidad del mismo. La filosofía integral del programa, donde se atiende a varios problemas en vez de uno solo, y el énfasis en el "proceso" en vez del "producto" hacen que su aplicación en otro contexto sea más difícil de lo que sería para proyectos enfocados en un sólo problema.

Los programas de bajo costo son más fáciles de extender. Sin embargo, todavía no se ha podido determinar si es posible diseñar programas económicos que funcionan eficazmente a gran escala, y se necesitan rigurosos análisis de los gastos. Debe abandonarse la idea de que la

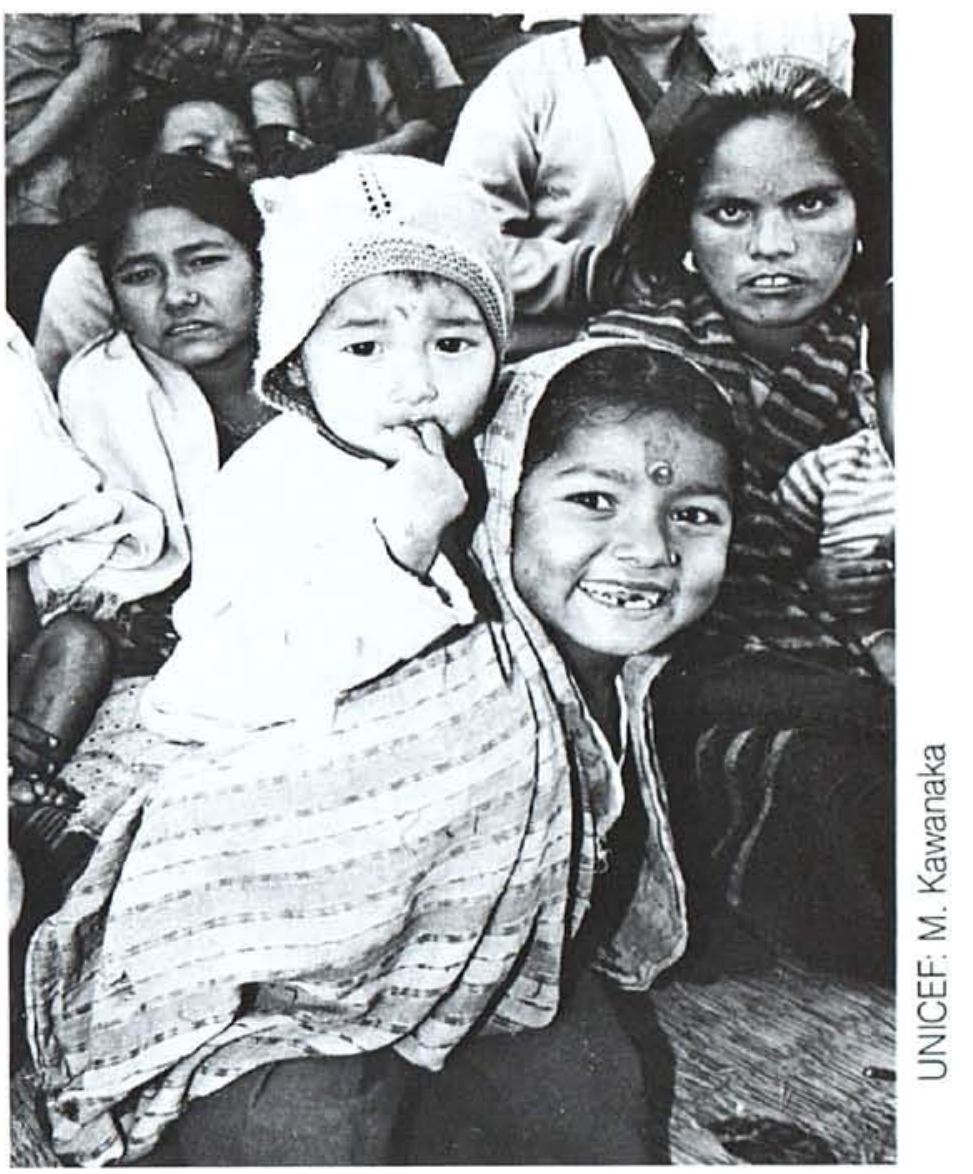

participación comunitaria no genera costos. Cuando las madres y otros miembros de la comunidad son los prestadores básicos de servicios, es preciso hacer importantes inversiones en capacitación y supervisión, y los supervisores también requieren apoyo profesional.

La instalación, los materiales y el entrenamiento necesarios para un grupo de cuidado infantil basado en el hogar, por ejemplo, le cuestan US\$ 120 al PCRW. Una vez que está en marcha, el grupo no requiere apoyo externo para su operación diaria. Aunque esta es una cifra relativamente baja, debe tenerse en cuenta que se trata de un programa en pequeña escala que recién empieza a operar. Todavía no se han determinado los costos del apoyo y el entrenamiento de seguimiento.

Se ha propuesto que la generación de ingresos podria ser el modo principal de lograr autosuficiencia, además de ser la conexión lógica entre los programas del PCRW para la mujer y para el desarrollo infantil. Los centros de cuidado infantil han avanzado en esta dirección mediante el cultivo de árboles frutales y la crianza de cerdos. Pero aunque estos centros sigan siendo los ejes principales del programa de desarrollo infantil, se espera que lleguen a funcionar principalmente como recursos de entrenamiento $y$ coordinación para una variedad de actividades complementarias en educación y cuidado infantil. 


\section{Ecuador: Programas Comunitarios de Cuidado Infantil en los Suburbios de Guayaquil}

Situada en las orillas del Río Guayas en la costa del Pacífico, la ciudad de Guayaquil es la segunda más grande del Ecuador, además de contener el puerto marítimo más importante del pais. Durante las últimas décadas la población de Guayaquil ha crecido de 260.000 habitantes en 1950 a 2.750.976 en 1989 (según cálculos del Instituto Nacional de Estadística y Censos), impulsada principalmente por el "boom" petrolero que, de 1972 en adelante, provocó el crecimiento industrial y aumentó las inversiones públicas en las regiones urbanas. Estos cambios provocaron una migración masiva a Guayaquil, con el crecimiento consecuente de asentamientos marginales y barrios pobres. Conocidos localmente como suburbios, estos vecindarios se caracterizan por condiciones de vida sumamente bajas, escasez de oportunidades de empleo, viviendas deficientes y falta de acceso a la infraestructura social.

\section{Identificando las necesidades}

Con el aumento del costo de vida en los suburbios en años recientes, las mujeres han tenido que contribuir más a los ingresos familiares, buscando empleos fuera del hogar a la vez que siguen cumpliendo sus responsabilidades domésticas. Cerca de un tercio de las mujeres que trabajan generan ingresos en el hogar, mientras que el $18,7 \%$ lo hace mediante un empleo formal. Más de la mitad del segundo grupo trabaja como sirvientas domésticas. Además, cabe señalar que más del $16 \%$ de todas las familias en los suburbios están encabezadas por una mujer.

Los niños que viven en los suburbios suelen sufrir de mala salud, ya que la higiene y las instalaciones sanitarias en estos barrios son muy deficientes y la desnutrición es común. Un estudio de las prácticas locales relativas al cuidado de los niños, realizado en 1988, encontró que las mujeres empleadas con niños pequeños suelen tener que encerrarlos en sus casas cuando salen a trabajar, o los dejan con una hija mayor, impidiendo que ésta concurra a la escuela.

\section{Tomando acción}

En 1979 UNICEF y el Gobierno de Ecuador iniciaron el Proyecto de Servicios Urbanos Básicos de Guayaquil, con el propósito de promover el desarrollo integrado de los barrios marginales de la ciudad. Reconociendo que el cuidado infantil era sumamente escaso y caro en los suburbios, el proyecto incorporó un componente con este fin en sus cuatro enfoques básicos: Cuidado Infantil Preescolar, Atención Médica Primaria, Comunicación Social y Recreación, y Promoción y Organización de la Mujer. El Programa de Cuidado Infantil Preescolar se inició en 1979. En 1983 el Programa de Promoción y Organización de la mujer empezó a funcionar bajo la égida de dos instituciones: la Oficina Nacional de la Mujer y el Instituto Nacional del Niño y la Familia (INNFA).

Los cuatro programas tienen como objetivo mejorar las condiciones de vida de los residentes de ciertos sectores urbanos marginales a través de la provisión de servicios y oportunidades eficaces y económicas que incorporan la participación de la comunidad en las etapas de diseño, implementación y evaluación de los proyectos. Lo singular de estos programas es que buscan responder a los problemas de los residentes de los sectores marginados a través de una variedad de actividades diferentes pero entrelazadas. El Programa de Promoción y Organización de la Mujer, por ejemplo, responde a las necesidades económicas de las mujeres de los suburbios con actividades directas para la generación de ingresos, mientras que el Programa de Cuidado Infantil Preescolar contribuye a este fin de modo indirecto, mediante la provisión de cuidado infantil bueno y confiable, el cual permite que la mujer trabaje durante el dia. El Programa Preescolar también crea oportunidades de empleo para dos grupos especificos de mujeres: las madres que cuidan niños en sus hogares y las estudiantes universitarias o de escuela secundaria que trabajan como promotoras. Además, el Programa de Atención Médica Primaria provee servicios para niños que participan en el programa preescolar.

\section{Implementando el programa de cuidado infantil}

Como el programa en Nepal, el Programa de Atención Preescolar Integrada emplea dos modelos aplicables al contexto urbano: el Hogar Comunitario y el Centro Comunitario. El modelo del Hogar Comunitario Infantil $(\mathrm{HCl})$ utiliza viviendas locales para proveer cuidado a los hijos de madres que trabajan. En la versión ecuatoriana de este modelo, la casa le pertenece a una vecina que ha sido capacitada para trabajar como cuidadora infantil de modo permanente. La cuidadora dispone de una asistente que también ha sido 
capacitada por el programa. Generalmente unos 15 niños de entre 3 meses y 6 años de edad pasan entre 8 a 9 horas por dia hábil en cada $\mathrm{HCl}$.

El modelo del Centro Comunitario Infantil (CCl) ofrece cuidado para un máximo de 100 niños en un sitio provisto por la comunidad (un centro comunitario, una iglesia o un club deportivo). Estos centros aceptan a niños de entre 3 y 6 años de edad, cinco dias por semana, durante turnos de mañana o tarde que duran 3 a 4 horas. Los niños son atendidos por jóvenes promotoras elegidas por la comunidad y entrenadas por el proyecto.

Tanto las promotoras comunitarias como las madres cuidadoras son elegidas por la comunidad. Las madres cuidadoras deben poder leer y escribir, tener experiencia en la crianza de niños y poseer una casa adecuada para proveer buena atención a niños adicionales. Las promotoras comunitarias deben ser estudiantes secundarias o universitarias, residir dentro de la comunidad y disponer de tiempo para trabajar medio turno por día como asistentes de las cuidadoras. Las cuidadoras y las promotoras son supervisadas por profesionales de nivel universitario que tienen experiencia en programas de cuidado infantil. Para participar en el programa una familia debe reunir los siguientes criterios: sus ingresos totales deben ser bajos, la madre debe estar trabajando o buscando trabajo, la familia debe carecer de un miembro apropiado para el cuidado de los niños y sus miembros deben estar dispuestos a cumplir con los requerimientos del programa.

\section{El programa de promoción de la mujer}

Este programa busca mejorar la calidad de vida de las mujeres a través de la provisión de información, conscientización y entrenamiento, y por medio de la extensión de los papeles productivos de la mujer y la reducción de su carga de trabajo doméstico. El programa también motiva a las mujeres a que se organicen para resolver sus problemas y para que diseñen, ejecuten y evalúen sus propios programas sociales.

Además de organizar a las mujeres dentro de la comunidad, el programa de mujeres ha creado una Red Comercial de Alimentos Básicos compuesta de comerciantes "honestos", elegidos por la comunidad, que prometen vender alimentos básicos (arroz, azúcar, huevos, etc.) a precios justos, a cambio del acceso a los programas de crédito y capacitación operados por INNFA. En cooperación con varios bancos comerciales, el programa de mujeres también ha logrado establecer un sistema de préstamos para microempresarias, además de ofrecer una variedad de cursos de capacitación en ámbitos no tradicionales para la mujer, como mecánica automotriz y reparación de aparatos eléctricos. Aunque el programa le da prioridad a las mujeres, no necesariamente excluye a los hombres. Una mujer que pertenece a una de las organizaciones com-

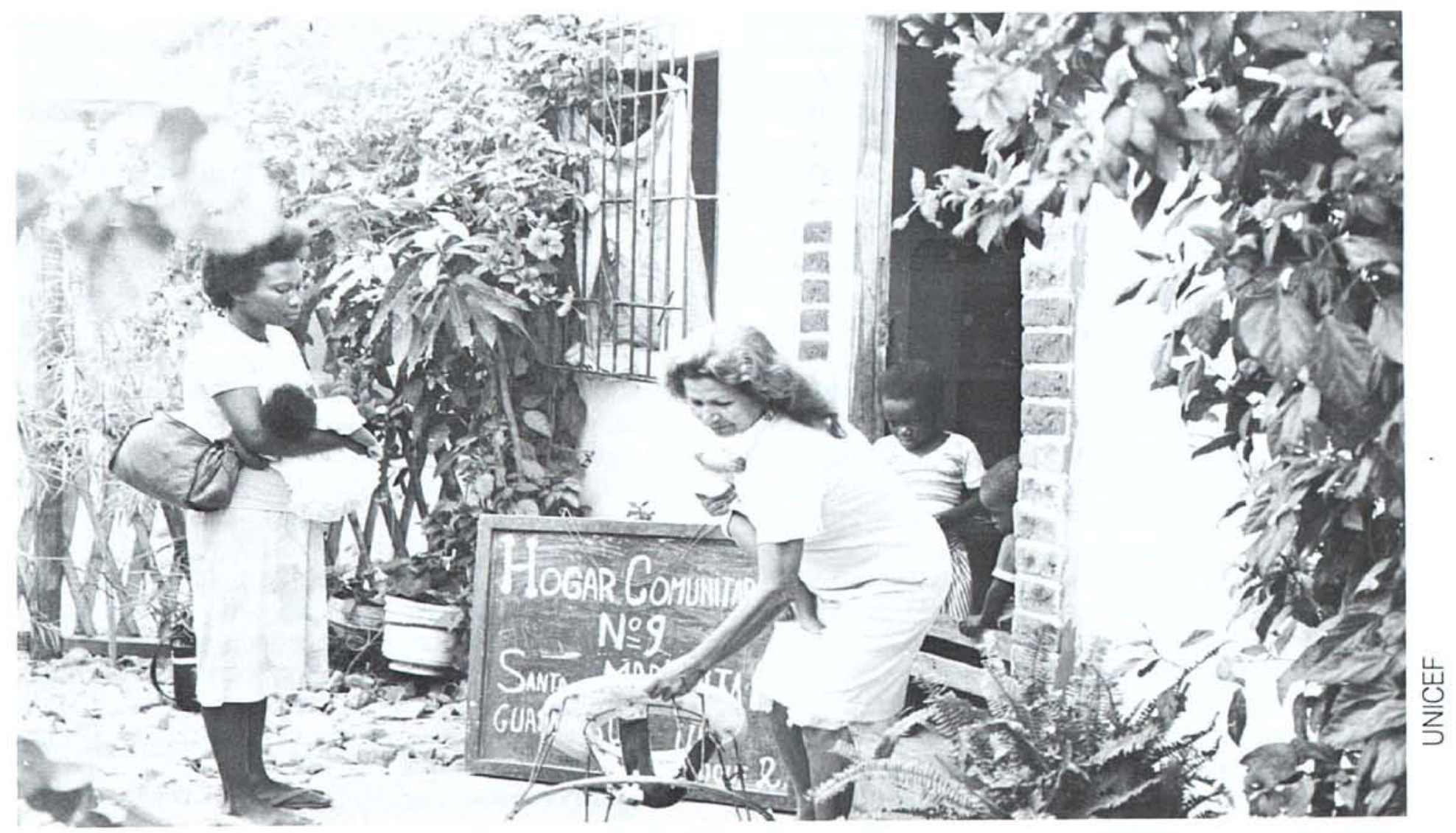


unitarias del programa también puede desempeñarse como promotora de salud y como madre cuidadora o promotora dentro del programa preescolar.

\section{Los programas preescolares}

En vez de operar como instituciones convencionales, los Hogares Comunitarios y los Centros Comunitarios buscan proveer el mejor cuidado infantil posible a través del uso creativo de los recursos comunitarios disponibles. Estos incluyen los recursos humanos (madres, jóvenes, dirigentes), los materiales (locales comunitarios, otros edificios) y los económicos (contribuciones de la familia del niño).

En el programa de cuidado en el hogar, las madres traen sus hijos a la casa designada a las 7 de la mañana, donde los recibe la madre cuidadora. Durante el día los niños participan en una variedad de actividades recreativas y estimulantes (pintura, recorte de papeles, canto, baile, etc.) y reciben un total de tres comidas.

\section{Doña Emperatriz}

Doña Emperatriz de Lara empezó a trabajar como madre cuidadora hace nueve años, y ha estado recibiendo niños en su casa continuamente desde entonces. Todos los habitantes del barrio conocen a Doña Emperatriz, a su esposo (un simpático sastre), y a sus tres hijas estudiantes. Su casa, la cual siempre está abierta para las visitas, es muy limpia y ha sido remodelada y ampliada. Aunque el programa preescolar indica que no debe haber más de 15 niños en cada casa, Doña Emperatriz suele cuidar 17 y a veces 18, porque no le gusta rechazar los pedidos de sus vecinas. "Este niño llegó hace tres meses, flaquito como un palo", dice la Doña, "iy ahora vea qué sano y gordito lo tenemos!"

En los centros de cuidado infantil los niños asisten desde las 8 de la mañana hasta el mediodia, o de las 14 hasta las 18 horas. La mayoria del tiempo se dedica a actividades de estimulación y recreación, y los niños también reciben una merienda. Generalmente se los divide en grupos por edad y cada promotora se encarga de un máximo de 25 niños.

\section{Anita}

Anita empezó a trabajar como promotora en un centro de cuidado infantil hace siete años, cuando recién habia terminado la escuela secundaria. Se destacó inmediatamente por su dinamismo con los niños, y por su inagotable energía. Poco a poco Anita empezó a ayudar a sus colegas, mostrándoles cómo llenar los formularios de concurrencia de los niños, cómo organi- zar y conducir reuniones con los padres, y cuáles eran las canciones y ejercicios favoritos de los niños. Posteriormente Anita fue designada como supervisora y contratada oficialmente por el Ministerio de Bienestar Social para proveer apoyo técnico a otras promotoras. El hecho de que Anita pertenece a la comunidad probablemente ayuda a que se la acepte más que a otras supervisoras y a que los padres de los niños en el centro confien en ella y sus consejos.

\section{Educación de madres, familias y comunidades}

Una de las actividades más importantes y más difíciles que realiza el programa es la educación de las madres que traen a sus hijos a los hogares o centros de cuidado. (Las sesiones educativas incluyen a madres e hijas; los padres y los hermanos están invitados a participar, pero generalmente no lo hacen.) Por un lado está el problema de las diferencias en los niveles educativos de las madres, y por otro el hecho que muchas trabajan en el centro de la ciudad (típicamente como sirvientas domésticas) durante demasiadas horas como para poder asistir a sesiones educativas. La falta de tiempo es aún más pronunciada para las madres que no tienen esposos o compañeros, y que por lo tanto cargan con muchas responsabilidades adicionales. En consecuencia, el intercambio educativo tiende a ocurrir día a día cuando las madres dejan y pasan a buscar a sus hijos, y durante reuniones bimensuales con el comité de padres en los Hogares Comunitarios.

\section{Factores que contribuyen al éxito del programa}

El Programa de Cuidado Infantil Preescolar satisface con eficacia una necesidad que la comunidad considera urgente. Para las madres que trabajan, los Hogares Comunitarios representan una solución conveniente y positiva al dilema del cuidado infantil. Para los padres, los Centros Comunitarios representan una oportunidad para asegurar el desarrollo social e intelectual de sus hijos, y sobre todo para prepararlos para escuela.

El costo de estos servicios equivale a un pequeño porcentaje de los ingresos de los padres y es notablemente bajo comparado con servicios privados similares. Sin embargo, el programa requiere que los padres participen activamente en la operación de los servicios mediante su asistencia a reuniones periódicas donde se discuten problemas económicos y logísticos como los suministros de alimentos, etc. Uno de los resultados positivos de esta participación es que los padres paulatinamente adquieren una mayor conciencia sobre el desarrollo de sus propios hijos. 


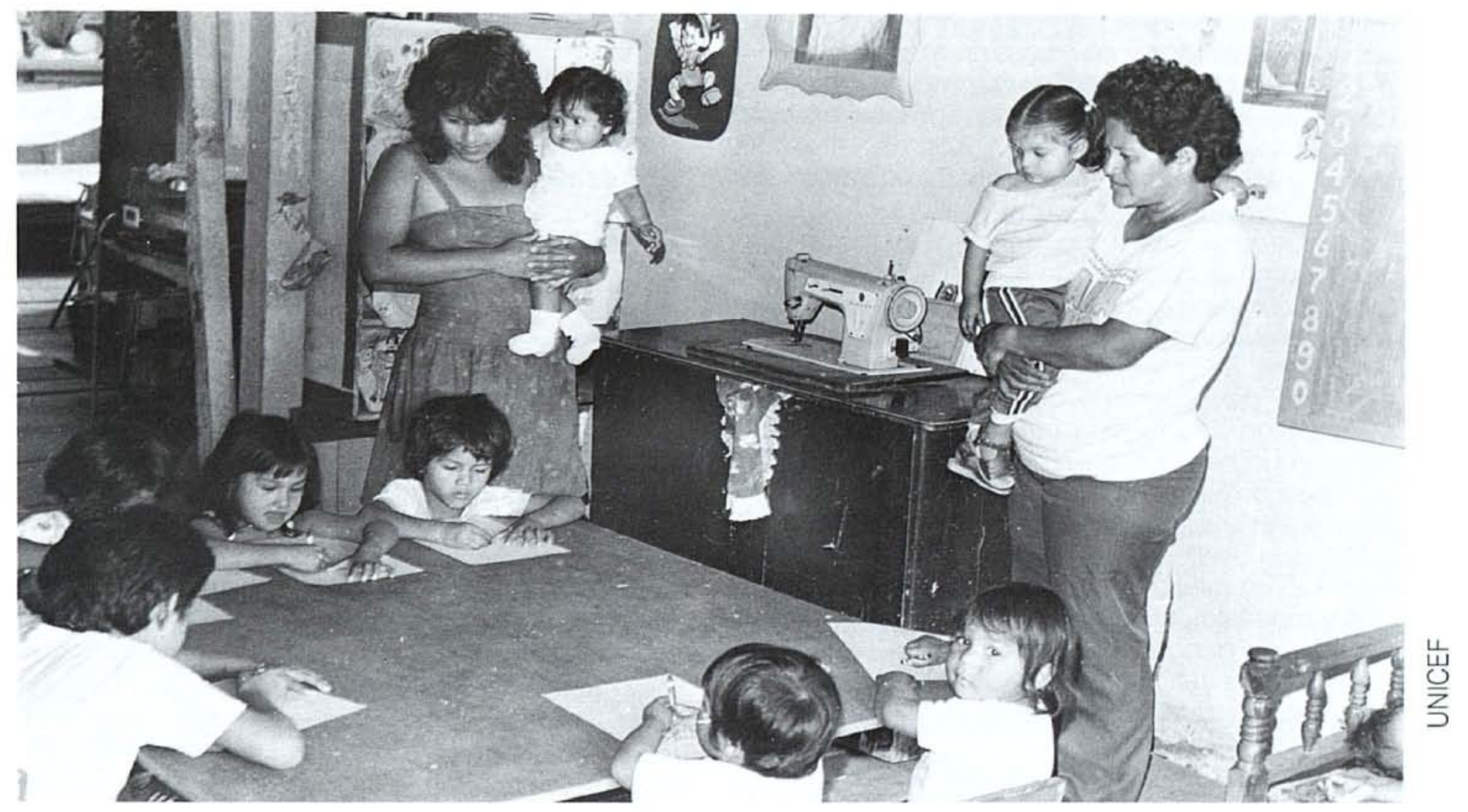

\section{Problemas}

Aunque el programa ha logrado movilizar a la comunidad hacia el apoyo del cuidado integral de los niños, también se han enfrentado una variedad de problemas burocráticos y políticos. Los procedimientos gubernamentales que determinan la contratación del personal o la distribución de fondos, por ejemplo, son lentos y complicados. $Y$ en algunas situaciones donde se decidió transferir ciertos recursos y poderes de decisión a una organización comunitaria, no se tomaron los pasos necesarios para preparar a la comunidad, ya sea en términos de capacitación o el establecimiento de mecanismos de control.

Varios dirigentes comunitarios responsables por la contratación de promotoras locales y madres cuidadoras han presionado indebidamente al Ministerio, logrando el nombramiento de parientes y amigos que no reunían los requerimientos establecidos para estos puestos. Otros dirigentes han usado su autoridad para pagarle al personal local con el fin de influir en las actividades, o para requerir un porcentaje de los sueldos como "honorario". Además, en los sectores marginales de una ciudad del tamaño de Guayaquil suele existir un intenso nivel de actividad política, creando una serie de presiones que las promotoras y las madres cuidadoras se ven obligadas a negociar.

\section{Resultados entre las mujeres, los niños y la comunidad}

Desde que empezó en 1979, el Programa de Cuidado Infantil Preescolar ha sido evaluado tres veces por equipos externos que han destacado los siguientes resultados. En el primer lugar, los dos modelos de cuidado infantil satisfacen una evidente necesidad de la comunidad. En el caso de las $\mathrm{HCl}$, por ejemplo, las madres pueden salir a trabajar o a buscar trabajo con la certeza de que alguien estará cuidando, alimentando y protegiendo adecuadamente a sus hijos. Asimismo, los $\mathrm{CCl}$ permiten que el niño desarrolle su potencial intelectual, emocional, físico y social. Ninguno de estos servicios existía en la comunidad antes de que se introdujera el proyecto. Sin embargo, la demanda actual por los servicios excede la capacidad de los programas.

El Programa de Cuidado Infantil Preescolar ha tenido un impacto considerable en la salud y el desarrollo nutricional y psicológico de los niños que participan. Aunque no se dispone de información actualizada, el testimonio de las madres cuidadoras indica que muchos de los niños que llegaron desnutridos a los hogares se han recuperado con rapidez. Obviamente, la atención, la alimentación regular y la prevención y el control de la diarrea han contribuido a la mejora del estado nutricional de los niños. Los niños que asisten a los hogares y los centros también tienen acceso al programa de vacunas del Ministerio de Salud.

Aunque resulta difícil medir el desarrollo psicosocial de los niños en términos concretos, es evidente que el programa ha tenido un impacto positivo en el proceso de socialización de los mis- 
mos. Los niños que participan en el programa son menos tímidos y se muestran más dispuestos a compartir cosas con sus compañeros. Su desarrollo lingüistico se puede apreciar en una mayor capacidad de expresión. Además, el ambiente de los hogares y centros comunitarios es mucho más estimulante que el de los hogares particulares de cada niño, donde la televisión funciona como el pasatiempo típico de los preescolares. (La mayoria de las familias en los suburbios tienen televisores.)

Para las madres que trabajan, el mayor beneficio del programa de cuidado infantil es la satisfacción y tranquilidad que sienten al dejar sus hijos en un hogar comunitario, donde saben que recibirán protección y atención completa mientras ellas están trabajando. Asimismo, los padres de niños que asisten a los $\mathrm{CCl}$ manifiestan que sus hijos se ven más alertas e inteligentes, menos tímidos y más listos para ir a la escuela. Sin embargo, los $\mathrm{CCl}$ no pueden responder eficazmente a las necesidades de la mayoría de las madres que trabajan, ya que sólo ofrecen cuidado durante medio turno por dia.

Para las proveedoras de cuidado infantil, las dos principales ventajas de la participación han sido el honorario (aproximadamente US\$ 35 por semana en 1988, lo cual equivalia al 40\% del salario de una maestra de escuela primaria), y la oportunidad de recibir entrenamiento en aspectos específicos de la acción social. La posibilidad de adquirir un mayor grado de influencia y prestigio dentro de la comunidad figura como otro importante incentivo.

\section{Los costos del programa}

Un equipo de evaluación (compuesto del Ministerio de Bienestar Social, el Consejo Nacional de Desarrollo y UNICEF) estimó que para 1983 el costo de cada $\mathrm{HCl}$ que sirve a 15 niños, incluyendo una inversión inicial de US\$210 y los gastos de operación, supervisión, apoyo técnico y control, llegaba a US\$ 1850 por año. Para los CCI la inversión inicial se estimó en US\$876, mientras que los gastos de operación, supervisión, apoyo técnico y control se calcularon en US\$ 2620 por año.

Inicialmente el $80 \%$ del financiamiento para el programa provenia de UNICEF, y las instituciones nacionales cubrian el 20\% restante. Los planificadores del proyecto incluyeron un mecanismo para aumentar las contribuciones de instituciones nacionales de tal modo que el aporte de UNICEF pudiera disminuir paulatinamente. El mecanismo ha funcionado bastante bien, excepto algunos obstáculos causados por la lentitud e ineficacia de los procesos de financiamiento del sector público y por la centralización excesiva de las decisiones financieras en la capital federal. Pese a estas dificultades, el INNFA actualmente cubre el costo total del Programa para Mujeres y el Ministerio de Bienestar Social carga con el 90\% del costo total del Programa de Cuidado Infantil.

\section{Mirando hacia el futuro}

Desde 1979, cuando se fundaron los primeros hogares comunitarios, el Ministerio de Bienestar Social ha logrado extender el programa a casi toda la nación. En 1987 existían $69 \mathrm{HCl}$, $109 \mathrm{CCl}$, y 10 Centros Caseros (un nuevo modelo), los cuales servian a un total de 55.222 niños y 38.653 familias participantes en Guayaquil. El gobierno nacional que asumió el poder en agosto de 1988 se comprometió a extender la cobertura a 108.000 niños en el pais entero, a través de la creación de una Red de Cuidado Infantil Comunitario.

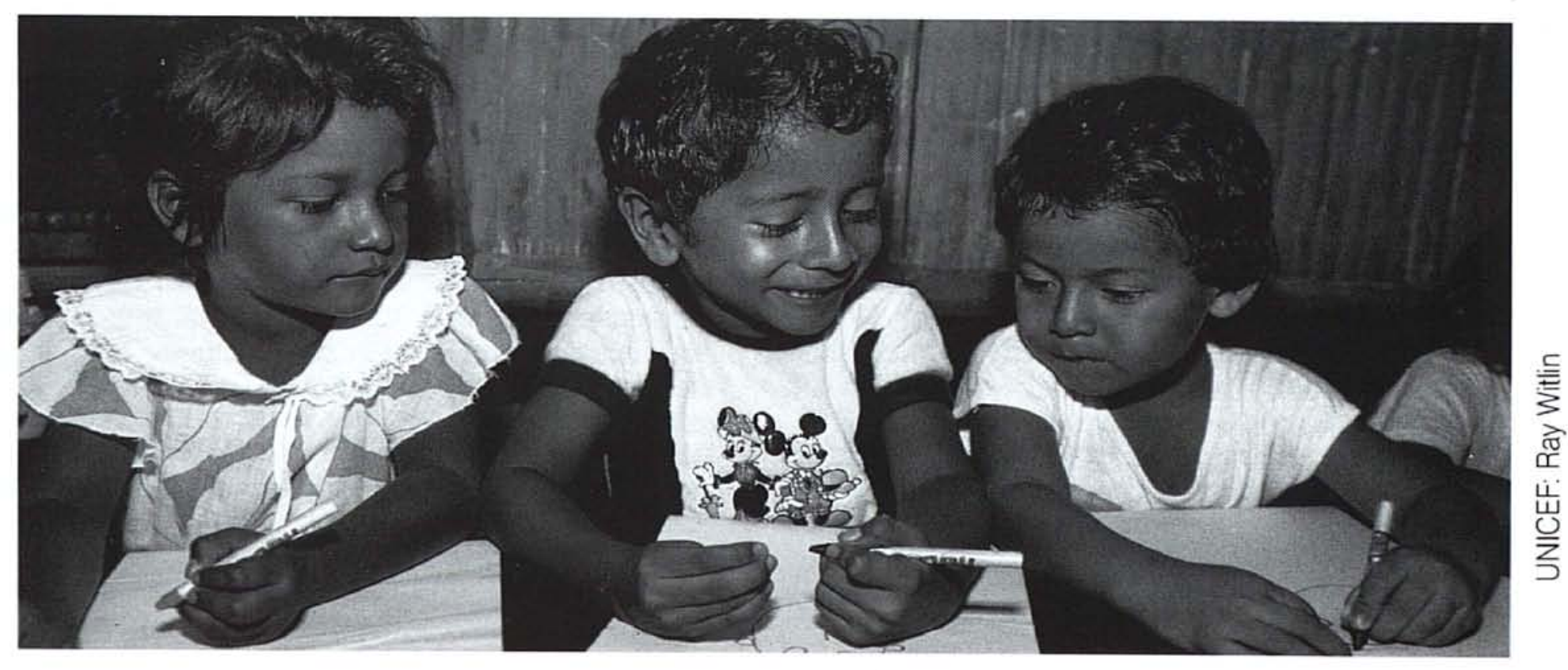




\section{Etiopía: Cuidado Infantil para Cooperativas Agrícolas}

La Cooperativa de Productores Agricolas de Melka Oba está situada a unos $120 \mathrm{~km}$. al sureste de Addis Ababa, la capital de Etiopía. Accesible por camino durante el año entero, la cooperativa se encuentra en una planicie rodeada por montes, a través de la cual corre el rio Awash. Es una región calurosa y árida, donde cae muy poca lluvia, por lo cual resulta difícil depender de la agricultura para la subsistencia. Excepto algunos arbustos y árboles de fruta, la tierra ha sido completamente desforestada.

Como parte del programa de reforma agraria de Etiopia, 192 familias agricultoras de la región de Harrarghe fueron trasladadas a Melka Oba por el gobierno, donde se les entregaron 155 hectáreas que le habian pertenecido a un empresario privado. Los agricultores, que incluian 103 hombres y 89 mujeres, 124 niños menores de 9 años de edad y 34 entre 10 y 15 años, se organizaron para formar una cooperativa de productores de frutas y vegetales para el mercado local.

Las tareas agricolas de la cooperativa se distribuyen entre 6 equipos de trabajadores: dos para los huertos, dos para la producción de cereales, uno para el cultivo de vegetales, y dos que sirven como guardias contra ladrones y animales silvestres. La cooperativa también recibe la asistencia de un organizador, un asistente en economia doméstica y un equipo de técnicos en desarrollo provistos por el Distrito de Woreda del Ministerio de Agricultura. Cada miembro de la cooperativa recibe un ingreso mensual promedio de 120 Birr (aproximadamente US\$ 58). Este sueldo está basado en puntos laborales equivalentes a siete horas de trabajo por dia, seis dias por semana.

\section{Identificando las necesidades}

Una evaluación de la situación en Melka Oba previa al inicio del proyecto de cuidado infantil reveló que las mujeres cargaban con una mayor proporción del trabajo que los hombres. Sus tareas agricolas y domésticas les dejaban muy poco tiempo libre. No se disponia de servicios de salud materno-infantil y los niños no recibian atención médica adecuada. La comunidad carecia además de una fuente confiable de agua potable, y el medio ambiente en general estaba bastante contaminado. En consecuencia se estaba registrando un índice de mortalidad infantil demasiado alto, y muchos de los niños padecian problemas de salud comunes como diarrea, gastroenteritis, conjuntivitis, paludismo e infecciones respiratorias y del oído.
Las madres pertenecientes a la cooperativa recibían sólo 45 dias de licencia materna, luego de la cual volvian a trabajar el dia entero, principalmente en los campos. Como consecuencia de esta práctica se habia manifestado un pronunciado descenso en la lactancia materna. Además, una vez que las madres volvian a trabajar sus criaturas recibian muy poca atención, quedando deprivadas del ambiente necesario para un buen desarrollo físico, social y mental. En la ausencia de sus madres y padres, la mayoria de los niños pequeños quedaban solos o bajo la atención de un hermano o una hermana mayor. Aunque una escuela primaria quedaba a sólo $6 \mathrm{~km}$. de la cooperativa, la falta de un centro de cuidado infantil hacia necesario que la comunidad empleara a los niños de 6 a 10 años de edad como cuidadores infantiles en vez de mandarlos a estudiar.

En las peores situaciones algunos padres cerraban sus casas con llave cuando se iban a trabajar a los campos, para que sus hijos no se quedaran adentro. La proximidad del río a las casas aumentaba la posibilidad de que un niño se ahogara, y la abundancia de animales salvajes y viboras creaba un peligro continuo. En este contexto los niños tampoco eran alimentados oportuna o adecuadamente. En conjunto, la ausencia de un centro de cuidado infantil, las deficiencias en los servicios clínicos, y la falta de agua potable, letrinas subterráneas y pozos para la basura contribuian a un ambiente amenazante para las mujeres y los niños. A todo esto se sumaba la actitud tradicional de los varones hacia las mujeres, la cual tenia por sentado que el cuidado infantil era la responsabilidad exclusiva de la mujer: algo que debía realizar por encima de sus extensas tareas domésticas y su trabajo agricola.

\section{Tomando acción}

En 1982 la cooperativa solicitó la asistencia de los administradores del distrito para establecer un de centro cuidado infantil. La cooperativa estaba dispuesta a hacer todo lo posible para crear el centro, siempre y cuando recibiera el apoyo técnico y material necesario. La situación de las mujeres y los niños de Melka Oba se llevó a la atención del Proyecto de Educación Integrada sobre Vida Familiar (IFLE), un agencia semiautónoma supervisada por el Ministerio de Trabajo y Asuntos Sociales y financiada principalmente por UNICEF. EI IFLE ha estado operando programas integrales en educación sobre vida familiar durante varios años. 
En enero de 1983, el IFLE estableció un Comité Interinstitucional (compuesto por la Comisión Nacional para la Niñez, los Ministerios de Salud y Agricultura, y UNICEF) con el propósito de identificar las necesidades de la Cooperativa Melka Oba y buscar soluciones para mejorar las condiciones de vida en la misma.

Se consideró urgente la instalación de una guardería infantil y un jardín de infantes que servirian también como un punto de entrada para otras iniciativas en supervivencia infantil y la promoción de servicios sociales. El proyecto buscó desarrollar un programa con los siguientes objetivos: 1) asegurar la seguridad y el cuidado apropiado de los niños mientras sus madres están trabajando; 2) permitir que las madres interrumpan su trabajo para amamantar a sus bebés;

3) proveer servicios regulares de inmunización; 4) desarrollar un programa para controlar el crecimiento y desarrollo normal de los niños; 5) proveer programas integrales de educación en vida familiar a los hombres y mujeres de la comunidad, abordando temas como salud, cuidado infantil, nutrición, planificación familiar, sanidad ambiental (eliminación de basura, construcción de letrinas, etc.); 6) aliviar algunas de las dificultades enfrentadas por las mujeres en la provisión de agua y combustible para el procesamiento y la preparación de alimentos, etc.; 7) disminuir la carga laboral de los agricultores mediante la aplicación de tecnología apropiada (básica), como son las carretillas de madera para transportar fruta a los puntos de recolección; y 8) capacitar a las parteras tradicionales.

\section{Implementación}

La estrategia interinstitucional que se empleó para el proyecto distribuyó responsabilidades entre varias organizaciones. El IFLE asumió la responsabilidad de implementar el programa con 36.100 Birr (US\$ 17.388) provistos por UNICEF.

En la primera fase del proyecto se instaló un programa integral de desarrollo infantil que posteriormente sería administrado por un comité de asuntos infantiles compuesto de vecinos elegidos por los miembros de la cooperativa. Los fondos provistos por UNICEF se utilizaron para:

- contratar durante ocho meses a un consultor local para entrenar a cuidadores de niños e instalar el centro de cuidado infantil;

- cubrir el costo de entrenamiento de las cuidadoras, las cuales serian residentes de la comunidad elegidas por los miembros de la cooperativa;

- comprar los materiales básicos necesarios para crear los materiales educativos y recreativos requeridos durante el período de entrenamiento;

- abastecer a la guardería infantil y el jardín de infantes con equipo interior y exterior;

- comprar herramientas básicas requeridas

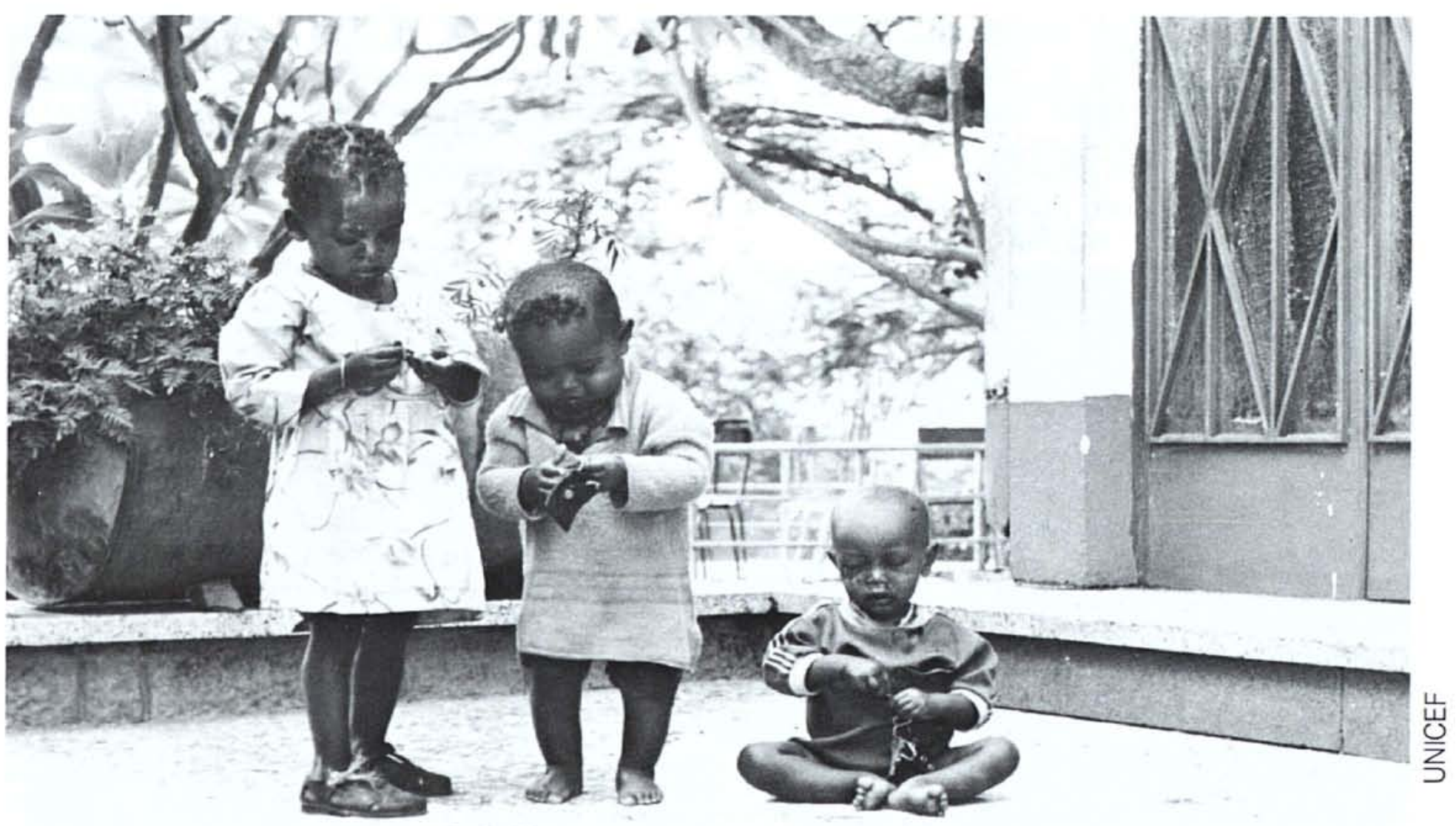


por las cuidadoras para producir materiales educativos y recreativos.

\section{Entrenamiento, organización, y administración}

La cooperativa consiguió una amplia casa de campo en la cual se instalaron la oficina del comité ejecutivo de la cooperativa y los salones de la guarderia infantil y el jardin de infantes. La Comisión Nacional para la Niñez proporcionó los reglamentos y las pautas en cuanto al cuidado y desarrollo infantil, y ayudó a conseguir un entrenador para las cuidadoras.

Aster Wolde Giorgis, la entrenadora de cuidado infantil, tiene unos 35 años. Luego de trabajar como maestra preescolar durante varios años, su singular capacidad para la creación de materiales educativos y recreativos la llevó a participar en un proyecto piloto para el entrenamiento de maestras preescolares apoyado por UNICEF. Cuando surgió la necesidad de capacitar a madres de limitada alfabetización en Melka Oba, Aster fue elegida como entrenadora principal. Su habilidad para adaptarse a las distintas regiones y culturas de Etiopia le ayudó a engendrar la confianza de la comunidad local. Su capacitación en psicologia moderna, desarrollo infantil, nutrición y salud le ayudaron a persuadir a la comunidad de que deberian cambiar algunas prácticas negativas en el cuidado infantil. A la misma vez, Aster pudo incorporar las tradiciones locales de una manera positiva al elegir cuentos infantiles $y$ canciones apropiadas para las regiones de origen de los miembros de la cooperativa. Aster también pudo aplicar su capacidad especial para la producción de materiales educativos y recreativos hechos con herramientas simples y materiales disponibles en la localidad.

Durante el período de entrenamiento Aster vivió en la comunidad con las mujeres que estaba capacitando. Además de conducir clases para cuidadoras en turnos de día y noche, organizó discusiones para todos los miembros de la cooperativa sobre temas como nutrición, higiene personal, economía doméstica y administración del cuidado infantil. Durante su estadia llegó a ser amiga personal de las cuidadoras que entrenó, y se ganó el respeto de toda la comunidad.

Más allá de su capacidad especial para el cuidado infantil, Aster posee una singular dedicación a su trabajo, y una facilidad para adaptarse a distintas condiciones de vida locales. Sus esfuerzos representan una importante contribución a la promoción del cuidado infantil en la Etiopia rural.

Los miembros de la cooperativa eligieron a las cuidadoras infantiles en base a su expresión de interés en el trabajo y su nivel educativo, el cual variaba entre el alfabetismo mínimo y el sexto grado escolar. El entrenamiento se realizó en el sitio y duró ocho meses, incluyendo unidades sobre el trabajo creativo y la producción de materiales, el desarrollo infantil, nutrición e higiene, medio ambiente, música, baile tradicional y arte.

Se capacitó a un total de 8 cuidadores (seis mujeres y dos hombres). Una joven de 22 años que ha completado ocho años escolares $y$ ha sido capacitada por el Instituto Nacional para el Entrenamiento de Maestras en Cuidado Infantil fue nombrada para encabezar el centro de cuidado infantil. La joven se encarga de la administración diaria del programa, y ha demostrado ser entusiasta y eficiente en el cumplimiento de sus responsabilidades. La cooperativa apoya al centro de cuidado infantil con un fondo especial reservado para el desarrollo social.

\section{El programa de cuidado infantil}

El centro empezó con 100 niños; la guarderia se encarga de los que tienen entre 45 dias y cuatro años de edad, y el jardin de infantes atiende a los de cuatro a seis años. El centro mantiene un horario flexible, y trata de coordinar sus servicios con las horas de trabajo de las madres. Las madres que tienen bebés ahora pueden visitar la guarderia varias veces por dia para amamantarlos, lo cual hace posible la continuación de la lactancia durante más tiempo de lo que se podia cuando los niños tenian que quedarse en casa. Un dia típico en el centro incluye varias actividades bajo techo y al aire libre. Los planes de enseñanza diaria tratan de ser paralelos al programa preescolar nacional, y el centro provee servicios de inmunización y salud.

\section{Otras actividades}

Antes de que se instalara el centro de cuidado infantil en 1983, Melka Oba no disponia de servicios sociales. La existencia del programa de cuidado infantil ha afectado profundamente a la cooperativa, cuyos miembros han empezado a estar conscientes de la necesidad de disponer de otros servicios. El Ministerio de Salud ha destinado un asesor de salud al programa, el cual cuenta con un Asistente Comunitario de Salud que ha sido entrenado durante seis meses en un centro de capacitación agrícola cercano. La unidad de salud maternoinfantil del Ministerio de Salud, la Asociación de Consejería Familiar de Etiopia y el IFLE han proporcionado entrenamiento en educación sobre vida familiar y planificación familiar a varios miembros de la cooperativa, los cuales han instalado un programa de salud. EI IFLE sigue apoyando a la cooperativa y de vez en cuando supervisa actividades comunitarias. 


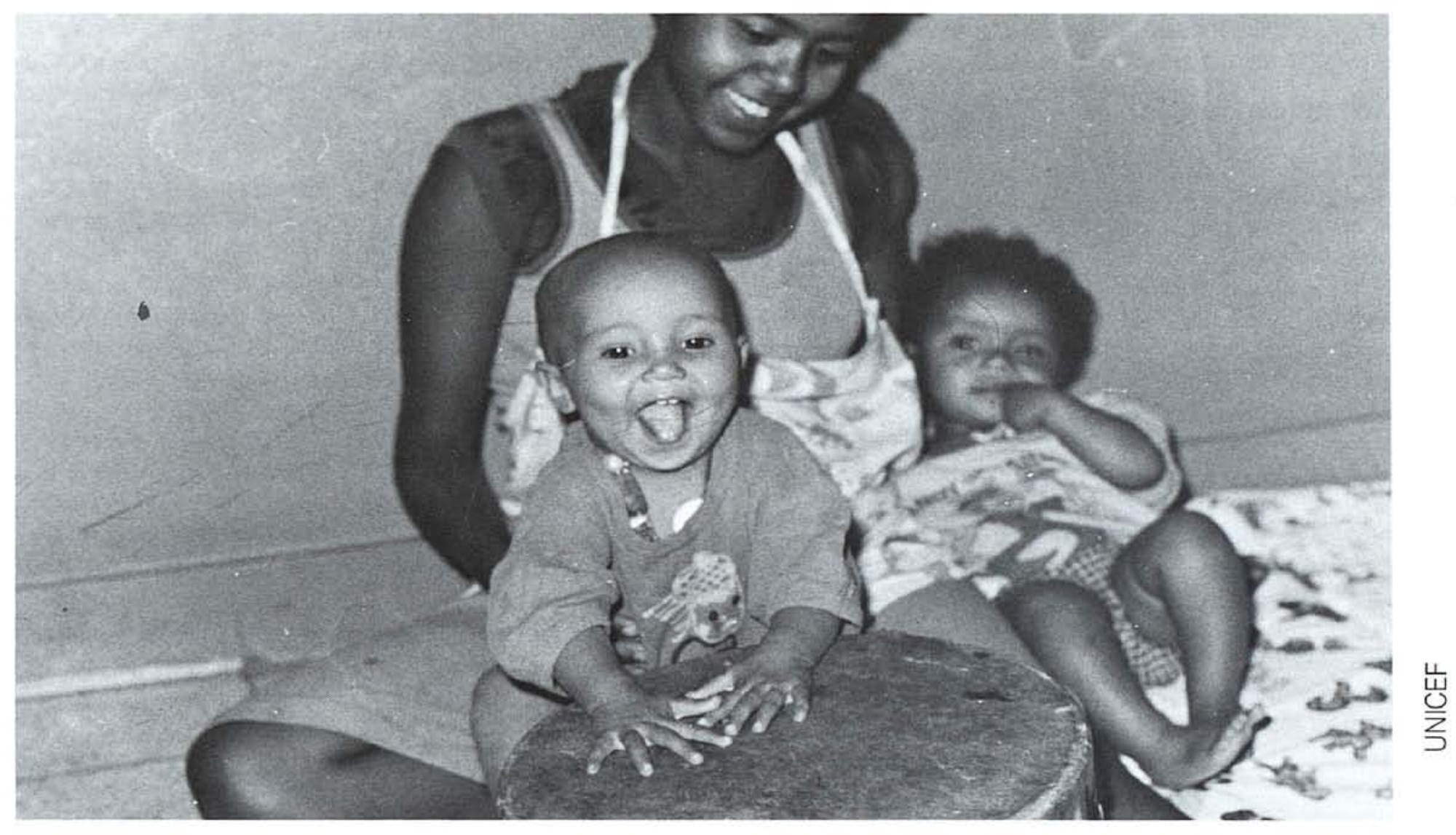

\section{Resultados entre las mujeres, los niños y la comunidad}

Durante las primeras etapas del desarrollo del proyecto, el Comité Interinstitucional, y particularmente el IFLE y UNICEF, decidieron realizar evaluaciones en el sitio, y si las circunstancias lo justificaran, una evaluación total del programa. En 1985, el Dr. Andargatchew Tesfaye, Profesor Asociado en la Universidad de Addis Ababa, visitó el proyecto y entrevistó al personal de la agencia que lo estaba implementando.

El Dr. Andargatchew opinó que dados los problemas y las condiciones previas relativas al cuidado infantil, la instalación de la guarderia y el jardin de infantes en Melka Oba había proporcionado un alivio oportuno para los padres de la localidad, y especialmente para las madres que trabajan. Todos los padres entrevistados por el Dr. Andargatchew indicaron que habian notado cambios concretos en la salud de sus hijos desde la aparición del programa. El Asistente de Salud y el Agente de Salud Comunitaria de Melka Oba confirmaron estos testimonios.

El nivel de producción de la cooperativa también ha aumentado ahora que las mujeres pueden concentrarse en sus tareas sin tener que preocuparse por sus hijos. El ausentismo laboral ha disminuido a medida que menos mujeres han tenido que llevar hijos enfermos a las clínicas. Además de proveer un ambiente relativamente sano y un régimen alimenticio equilibrado, el cuidado infantil está satisfaciendo las necesi- dades de desarrollo de los niños y estimulando el aprendizaje en todos los sentidos (físico, social, emocional e intelectual). Esta base hace posible una transición menos problemática a la escuela y un mejor desempeño en la misma.

Todos estos logros crearon un nuevo problema cuando los padres de los niños que habian completado el jardín de infantes quisieron colocarlos en la escuela primaria. La escuela más cercana quedaba a unos $6 \mathrm{~km}$. de la cooperativa, y los niños más pequeños no podian caminar esa distancia en los días más calurosos. Habiendo invertido en la preparación preescolar de sus hijos, los padres querian asegurar que éstos pudieran continuar su educación, por lo cual presionaron al Ministerio de Salud y lograron que se instalara una escuela primaria en Melka Oba. La comunidad también ha iniciado un programa de alfabetización para adultos.

\section{Problemas}

El desafio principal del proyecto fue cambiar la actitud de la comunidad, y especialmente la de los hombres, sobre el cuidado infantil, proponiendo que requiere la colaboración de ambos padres y de la comunidad entera, en vez de ser responsabilidad exclusiva de las madres. Antes de empezar el proyecto, cuando el representante del IFLE le preguntó al lider de Melka Oba si pensaba que hacia falta un sistema de cuidado infantil, éste respondió que no, "iporque las mujeres se encargan de eso!" 


\section{Posibilidades de duplicación}

EI IFLE y UNICEF emplearon su experiencia en la promoción de iniciativas en desarrollo y supervivencia infantil para implementar el programa integral de Melka Oba. En menos de dos años el IFLE ayudó a instalar otro programa de cuidado infantil en la Cooperativa de Productores Agricolas de Yetnora, situada en el Distrito de Dejen, Región Gojjam.

\section{Lo que se aprendió}

1. Cualquier iniciativa para responder a la necesidad de cuidado infantil debe tomar en cuenta las necesidades de tres grupos: las madres que trabajan, los infantes y niños preescolares, y las proveedoras de cuidado infantil. Las necesidades de estos tres grupos no son contradictorias, sino que están inextricablemente entrelazadas. Sólo los programas que atienden a los tres grupos en conjunto podrán responder a las necesidades de desarrollo de los niños, mejorar la capacidad de generación de ingresos de las mujeres (al aumentar el tiempo disponible y reducir la ansiedad), y permitir que las mujeres y sus comunidades se involucren eficazmente en el bienestar de sus hijos.

2. Para responder de manera realista a las necesidades de las madres que trabajan, los servicios de cuidado infantil deben reunir cuatro criterios: a) ser fácilmente accesibles, b) estar disponibles durante los horarios de trabajo de las mujeres c) cobrar precios que las mujeres pueden pagar, y d) funcionar de tal modo que la mujer se siente segura de que su hijo está en buenas manos.

3. Para proveer cuidado de alta calidad, los programas deben exhibir las siguientes caracteristicas: a) un curriculum apropiado que incluye métodos de aprendizaje iniciados por el niño en un ambiente de apoyo positivo; b) selección y capacitación rigurosa del personal y provisión de una estrategia para la recapacitación periódica; c) una proporción adecuada en el número de niños y personal; d) apoyo administrativo que esté ligado a otros servicios integrales, como salud y nutrición; y e) control y evaluación eficaz del progreso de los niños participantes. ${ }^{17}$

4. Es importante distinguir entre las necesidades de las madres con niños muy pequeños y las que tienen hijos más grandes. El cuidado para infantes, por ejemplo, debe tratar de hacer posible que las madres sigan amamantando al bebé.

5. La eficacia de los programas comunitarios de cuidado en el hogar reside en la especialización de las mujeres participantes: aunque casi todas sean madres, unas pocas pueden cuidar a los hijos de las demás, o como el caso nepalés, se pueden turnar en base rotativa. La capacitación de mujeres locales para el cuidado infantil, además de fortalecer su sentido de dignidad, les proporciona una fuente de empleo. También crea un oportunidad para el desarrollo de relaciones solidarias entre mujeres que pueden conducir a la acción social para el cambio. El poder potencial de las mujeres, una vez que se organizan en grupos, es capaz de transformar sus propias vidas y las de sus hijos.

6. Una vez que han sido capacitadas, las cuidadoras deben ser apoyadas y remuneradas adecuadamente, no sólo para mantener un buen nivel de calidad en la atención, sino para evitar la rotación excesiva del personal. Las cuidadoras también requieren la ayuda de asistentes técnicos bien capacitados. A medida que un proyecto se extiende, es indispensable profundizar los conocimientos técnicos del personal y preparar individuos que puedan supervisar, motivar y orientar a las mujeres locales.

7. Los programas que requieren la participación activa de los padres y la comunidad en la planificación y operación diaria del servicio de cuidado infantil, fortalecen la capacidad de la comunidad de responder por sí misma a las necesidades de sus hijos, y mejoran la posibilidad de que el proyecto logre ser autosuficiente cuando se agotan los fondos exteriores. La provisión de personal, edificios, alimentos, juguetes, etc. por la comunidad ayuda a disminuir los costos, mientras que su participación en la organización y operación de los programas fortalece la voluntad colectiva de responder a las necesidades de los niños.

8. Un exitoso programa de cuidado infantil basado en la comunidad puede servir como punto de entrada para otras actividades de desarrollo como la educación para padres, atención médica, sanidad, educación sobre nutrición, alfabetización de adultos y generación de ingresos. Los buenos programas preescolares también aumentan la probabilidad de que el niño permanezca en la escuela una vez que empieza su educación formal. La eliminación de la necesidad de que las hermanas mayores cuiden a los infantes también hace posible que éstas pasen más tiempo en la escuela.

9. El uso de métodos y materiales de entrenamiento apropiados para el nivel educativo de las cuidadoras representa otro elemento crítico en la implementación y operación exitosa de programas de cuidado infantil basados en la comunidad. La enseñanza debe estar centrada en la alumna, reconociendo los aspectos beneficiosos de las prácticas tradicionales de crianza infantil y respetando los logros y conocimientos existentes de las mujeres locales. El enfoque debe estar en el desarrollo de capacidades prácticas para la resolución de problemas a través del sentido común, y en el fortalecimiento del sentido de confianza propia de las mujeres. 
10. Debe reconocerse que no existe una manera ideal de proveer cuidado infantil. Dada las amplias diferencias en las condiciones de trabajo de la mujer, ningún modelo individual será capaz de responder a todas las necesidades. La provisión del cuidado infantil en gran escala debe desarrollarse de tal manera que se pueda responder con flexibilidad a las necesidades y circunstancias particulares de cada comunidad. La aplicación de un proyecto piloto en otro contexto debe abordarse con cautela. En vez de intentar una duplicación exacta de un exitoso programa "modelo" (los cuales suelen ser el resultado de una combinación singular de individuos y circunstancias), es preferible establecer mecanismos para que distintos grupos locales puedan compartir recursos y cooperar en la resolución de problemas logísticos como, por ejemplo, la compra de suministros.

11. Aunque el cuidado infantil basado en la comunidad ofrece la mejor posibilidad de autosuficiencia una vez que se agota el financiamiento exterior, es esencial que continúe el seguimiento y apoyo a los proveedores locales de cuidado infantil. Por otro lado también debe evitarse el problema de regulación excesiva que suele acompañar al crecimiento de un programa. No obstante las buenas intenciones, la imposición de pautas demasiado restrictivas puede aumentar el costo y reducir la disponibilidad de los servicios de cuidado infantil. En la mayoria de los casos es preferible dejar el control de la calidad de los servicios en manos de las madres y la comunidad, ya que ésta debe juzgarse según el contexto particular.

12. Sin un compromiso político no se pueden proveer buenos servicios de cuidado infantil para madres que trabajan. Los formuladores de politicas deben reconocer las importantes contribuciones económicas de las mujeres y la relación innegable entre la capacidad de trabajo de la mujer y la disponibilidad del cuidado infantil. También deben entender el importante papel del cuidado preescolar en la formación de futuras generaciones capaces de responder a los desafíos nacionales, y deben reconocer el valor de las contribuciones de las cuidadoras de niños y asegurar que se las recompense adecuadamente por su trabajo.

\section{Notas}

1. Facts for Life (UNICEF, OMS y UNESCO). (Oxfordshire, U.K.: P\&LA, 1989.)

2. Dwyer, Daisy y Judith Bruce, editoras, A Home Divided (Stanford, CA: Stanford University Press, 1988.)

3. Leslie, Joanne y Mayra Buvinic, "Introduction," en Leslie y Paolisso, editoras, Women, Work and Child Welfare in the Third World. (Boulder, CO: Westview Press, Inc.)

4. Lloyd, Cynthia y Anastasia J. Brandon, "Women's Role in the Maintenance of Households; Poverty and Gender Inequality in Ghana. Monografia presentada en PPA, Washington, D.C., marzo de 1991. (New York: The Popu. lation Council.)

5. Schmink, Marianne, "Women in the Urban Economy of Latin America," en Schmink, Bruce and Kohn, editoras, Learning About Women and Urban Services in Latin America and the Caribbean. (New York: The Population Council, 1986.)

6. The Ford Foundation Letter, volumen 21, número 2. verano de 1990.

7. The World Almanac and Book of Facts. (New York: 1989)

8. Winikoff, Beverly, Michael Latham, Giorgio Soliamano, y otros, The Infant Feeding Study. Un informe sometido por el Population Council al USAID en cumplimiento con el Contrato no. AID-DSAN-C-0211, 1985.

9. Dwyer, Daisy and Judith Bruce, 1988

10. Tolbert, Kathryn, "Availability and Need for Day-Care Services in Mexico City". Informe para la Fundación Ford. (Ciudad de México: The Population Council, 31 de mayo de 1990.)

11. Tolbert, Kathryn, 1990.

12. Landers, Cassie. Innocenti Global Seminar Early Child. hood Development: Summany Report. (New York: UNICEF, Consultative Group on Early Childhood Care and Development, October, 1989.)

13. Anderson, Janine y Nelson Panzio, "Transportation and Public Safety: Services that Make Service Use Possible," en Schmink, Bruce y Kohn, editoras, Learning About Women and Urban Services in Latin America and the Caribbean. (New York: The Population Council, 1986.)

14. Tolbert, Kathryn, 1990.

15. Tolbert, Kathryn, 1990

16. Mejia, Jorge, Memorándum para Cassie Landers, 28 de enero de 1991. Whitebook, M., C. House and D. Philips, Who Cares? Child Care Teachers and the Quality of Care in America. National Child Care Staffing Study. (Oakland, CA: Child Care Employees Project, 1989.)

17. Landers, Cassie, 1989. 
Diseño: Ann Leonard

Tipografia: Village Type \& Graphics

Foto de la portada: UNICEF: M. Kawanaka

Imprenta: Graphic Impressions, Inc.

Traducción: Paul Constance

Una versión más completa de los tres estudios (Nepal, Ecuador y Etiopía) esta disponible en la publicación Working Women and the Need for Child Care: Opportunities for Programmatic Collaboration, Cassie Landers y Ann Leonard, editoras (en inglés). Copias están disponibles de the Consultative Group on Early Childhood Care \& Development, UNICEF House, 3 United Nations Plaza, New York, NY 10017, U.S.A.

Tanto sus comentarios como sus ideas sobre proyectos que puedan ser incluídos en futuros números de SEEDS, son bienvenidos. Si usted desea ejemplares adicionales de este número o le interesa que se le incluya en la lista de quienes reciben a SEEDS, sirvase escribir a:

Ann Leonard, Editor SEEDS

P.O. Box 3923

Grand Central Station

New York, New York 10163 U.S.A. 


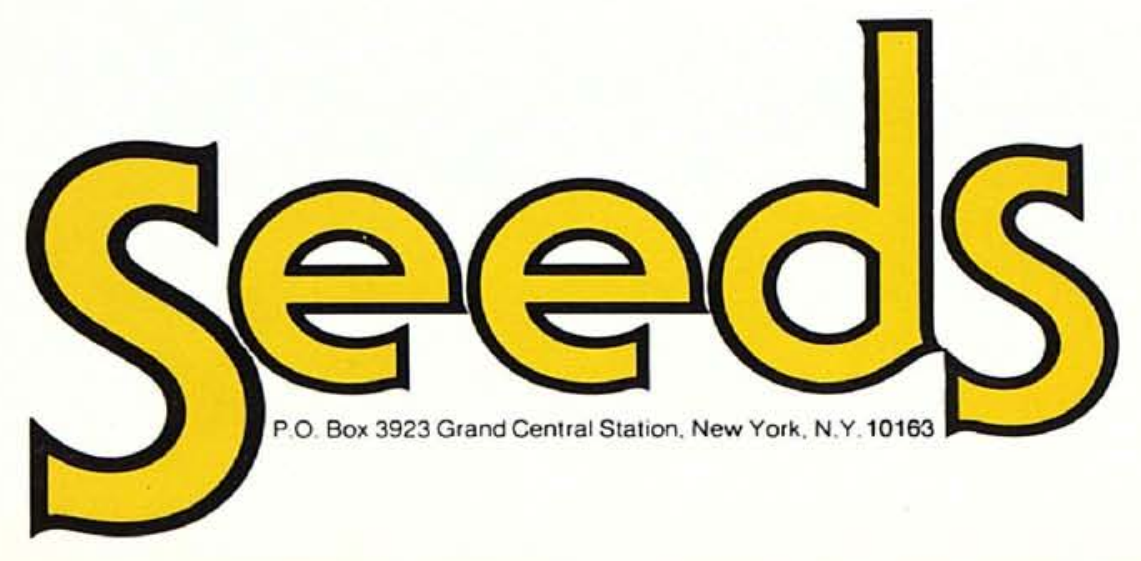

